\title{
Temperature development in structural stainless steel sections exposed to fire
}

\section{Gardner and K T Ng}

Imperial College London

\begin{abstract}
The initial material cost of structural stainless steel is about four times that of structural carbon steel, due largely to the expense of the alloying elements and the relatively low volume of production. Given broadly similar structural performance, additional areas of benefit need to be identified and exploited in order to establish stainless steel as a viable alternative material for construction. In addition to the familiar benefits of corrosion resistance, low maintenance, high residual value and aesthetics, one such area is fire resistance. The mechanical and thermal properties of stainless steel differ from those of carbon steel due to variation in chemical composition between the materials. A comparison of these properties for austenitic stainless steel with those for structural carbon steel is presented herein, and implications of the differences explored.
\end{abstract}

Accurate and efficient determination of the temperature development within a structural member upon subjection to fire is paramount. In this paper, comparisons of temperature development in structural stainless steel sections are made between existing test results, numerical simulations and the simple calculation model of Eurocode 3: Part 1.2. Based on these comparisons, revised values for the heat transfer coefficient and emissivity of structural stainless steel members exposed to fire are proposed. In the temperature development calculation model of EN 1993-1-2, it is proposed that emissivity be taken as 0.2 (in place of the currently adopted value of 0.4 ) and the heat transfer coefficient be taken as $35 \mathrm{~W} / \mathrm{m}^{2} \mathrm{~K}$ (in place of the currently adopted value of $25 \mathrm{~W} / \mathrm{m}^{2} \mathrm{~K}$ ). The significance of such revisions to the fire resistance and critical temperature is assessed. Application of the revised values in the predictive models for member resistances at elevated temperatures in Eurocode 3: Part 1.2 also 
reveals improved agreement with test results on axially loaded stainless steel columns in fire, and average enhancements in fire resistance of $10 \%$.

\section{Introduction}

The use of stainless steel in structural and architectural applications is growing due, in part, to the material's attractive appearance, corrosion resistance, ease of maintenance, low life cycle costs and fire resistance, alongside improved and more widespread design guidance and enhanced product availability. With heightened emphasis now being placed on the performance of structures at elevated temperatures [1], and an increasing trend towards the use of bare steelwork [2], a number of recent studies of the response of unprotected stainless steel structural members exposed to fire have been performed $[3,4,5,6]$.

Whether fire resistant design is based on a prescriptive approach or a performance based approach, or indeed whether isolated elements or complete structural assemblages [7] are considered, accurate and efficient determination of the temperature development within a structural member upon subjection to fire is paramount. Inaccurate evaluation of temperature development could lead to an increase in member size or an increase in the required level of fire protection. The cost of fire protection will vary from project to project, depending on required fire resistance, the size and type of structure and so on, but for multi-storey buildings, the fire protection costs are about $20-30 \%$ of the total cost of the steel frame [3,8]. Although there are some cost savings to be made by reducing the level (thickness) of fire protection, total elimination for the need of fire protection has far more substantial economic incentives. These may include lower construction costs, a shorter construction period, more effective utilisation of interior space and a better working environment [3]. For stainless steel structures, in addition to the economic incentives, exposure of the material surface has particular aesthetic appeal. Although a number of fire protection methods, such as intumescent paints, exist that do not impair aesthetics, these are generally at greater expense [9]. 
The mechanical and thermal properties of stainless steel differ from those of carbon steel due to variation in chemical composition between the materials. A comparison of these properties for austenitic stainless steel with those for structural carbon steel is presented herein - the austenitic grades of stainless steel being the most widely adopted in structural applications [10]. Elevated temperature strength and stiffness retention, thermal expansion, thermal conductivity, specific heat and unit mass are compared, and the significance of these properties on structural performance in fire is assessed. In addition to the mechanical and thermal properties of a material, the two key parameters for the determination of temperature development in structural members are the convective heat transfer coefficient and the emissivity (absorptivity). Both of these are a function of a range of factors including surface geometry and are therefore not material constants [11]; these factors are discussed later in more detail.

This paper concerns the behaviour of stainless steel in fire, and in particular examines the temperature development in structural stainless steel sections. Comparisons of temperature development in structural stainless steel sections are made between existing test results, numerical simulations (using the non-linear finite element package ABAQUS) and the simple calculation model of EN 1993-1-2 (2005) [12]. Based on these comparisons, revised values for the heat transfer coefficient and emissivity of stainless steel members exposed to fire are proposed. The significance of such revisions to the fire resistance and critical temperature of structural stainless steel members is assessed.

\section{Mechanical and thermal properties of stainless steel and carbon steel}

\section{Introduction}

Material properties and their response to elevated temperatures form an essential part of structural fire design. Of primary importance are the elevated temperature stressstrain characteristics, thermal expansion, thermal conductivity, specific heat and unit mass. A comparison between these properties for stainless steel and carbon steel is 
presented in the following sub-sections. Additionally, the two key parameters for the determination of temperature development in structural members, namely, the convective heat transfer coefficient and the emissivity (absorptivity) are introduced.

\section{Strength and stiffness retention}

The ability of a material to retain strength and stiffness at elevated temperature is crucial for achieving fire resistant structures. At elevated temperatures, stainless steel offers better retention of strength and stiffness than carbon steel, due to the beneficial effects of the alloying elements. A comparison of the elevated temperature performance of stainless steel and structural carbon steel is presented in Figures 1 and 2; the data are given in EN 1993-1-2 (2005) [12] and the Euro Inox/SCI Design Manual for Structural Stainless Steel [13]. Neither the US nor the Australia/New Zealand structural stainless steel design standards, which are amongst the most sophisticated, currently cover fire design. The strength reduction factors shown in Figure 1 are for grade 1.4301 (304) austenitic stainless steel [14], the most widely adopted grade for structural applications, whereas the stiffness reduction factors are common to all grades (austenitic, ferritic and duplex) included in the design guidance. The strength reduction factor $k_{y, \theta}$ is defined as the elevated temperature strength at $2 \%$ total strain $f_{2 \%, \theta}$, normalised by the room temperature $0.2 \%$ proof strength $f_{0.2 \%}$. The stiffness reduction factor $\mathrm{k}_{\mathrm{E}, \theta}$ is defined as the elevated temperature initial tangent modulus $\mathrm{E}_{\theta}$, normalised by the initial tangent modulus at room temperature E. It should be noted that the minimum specified room temperature $0.2 \%$ proof strength for the most common structural grades of austenitic stainless steel typically ranges between 210 and 240 $\mathrm{N} / \mathrm{mm}^{2}$, whilst the Young's modulus is $200000 \mathrm{~N} / \mathrm{mm}^{2}$ [15].

The comparison demonstrates that carbon steel and stainless steel display distinctly different behaviour at elevated temperatures. From Figure 1, it can be seen that carbon steel retains its full (room temperature) strength up to about $450^{\circ} \mathrm{C}$ whereupon it drops rapidly to only about $10 \%$ of its room temperature strength at $800^{\circ} \mathrm{C}$. At low temperatures, stainless steel has a reduction factor of greater than unity due to use of the $2 \%$ strain limit at elevated temperatures and the substantial strain hardening that stainless steel exhibits, but this extra strength degrades relatively rapidly. By $200^{\circ} \mathrm{C}$ 
stainless steel retains around $90 \%$ of its room temperature strength, falling to around $75 \%$ at $500^{\circ} \mathrm{C}$. The curves show that above $500^{\circ} \mathrm{C}$ which is the important temperature region for structural fire design, stainless steel has better strength retention than carbon steel. For a fire resistance of 30 minutes, material will be exposed to temperatures in excess of $700^{\circ} \mathrm{C}$, following the standard fire curve of ISO 834-1 (1999) [16] and EN 1991-1-2 (2002) [17].

Figure 2 compares the elevated temperature stiffness of stainless steel and carbon steel. For stainless steel, the stiffness reduces approximately linearly with temperature up to $700^{\circ} \mathrm{C}$, at which point it retains $70 \%$ of its room temperature stiffness before falling away more rapidly at higher temperatures. The elevated temperature stiffness of carbon steel degrades far more significantly, reducing to only $13 \%$ of its room temperature value at $700^{\circ} \mathrm{C}$. Both converge to zero stiffness at $1200^{\circ} \mathrm{C}$.

\section{Thermal expansion}

All metals expand when heated. Typically during component tests in fire, structural members will be free to expand against the applied load, and thus no additional load is induced due to this expansion. However, in structural frames, where continuity exists between members and often fire is relatively localised, thermal expansion may be restrained by other (stiffer) parts of the structure, resulting in additional member loading. Further consequences of thermal expansion may include higher axial and lateral member deformations and increased member forces and moments due to second order effects.

Figure 3 shows a comparison of the thermal expansion of carbon steel and stainless steel as given in EN 1993-1-2. The figure shows that stainless steel expands to a greater extent, up to $50 \%$ more than carbon steel. The effect of the higher thermal expansion has not been observed directly since no tests have been conducted on restrained stainless steel members or frames in fire. However, given the greater thermal expansion and the ability to retain strength and stiffness to higher temperatures, additional forces will be experienced by restrained stainless steel structural members. The severity of the additional member forces will depend on the applied loading 
arrangement and on the degree of rotational and translational restraint. It is clear that the additional member forces due to restrained thermal expansion may have a dominating effect over the superior strength and stiffness retention in some configurations. A numerical study of the influence of the higher thermal expansion is currently being performed by the authors.

\section{Thermal conductivity}

The variation of thermal conductivity with temperature is distinctly different for stainless steel as compared to carbon steel, as illustrated in Figure 4 [12]. The thermal conductivity of carbon steel is about $53 \mathrm{~W} / \mathrm{mK}$ at room temperature and reduces steadily with temperature to a value of $27 \mathrm{~W} / \mathrm{mK}$ by approximately $800^{\circ} \mathrm{C}$. In this temperature region $\left(723^{\circ} \mathrm{C}\right)$ a phase transformation occurs and the thermal conductivity subsequently remains constant. Stainless steel displays the opposite tendency, with increasing thermal conductivity with time. The relationship is continuous with temperature since no phase transformation occurs in austenitic stainless steel upon heating, increasing from about $15 \mathrm{~W} / \mathrm{mK}$ at room temperature to a value of about 30 $\mathrm{W} / \mathrm{mK}$ at $1200^{\circ} \mathrm{C}$.

For temperatures below about $1000^{\circ} \mathrm{C}$, the thermal conductivity of stainless steel is lower than that of carbon steel; at low temperatures the difference is significant, whilst above about $700^{\circ} \mathrm{C}$, the difference is small. The effect of lower thermal conductivity will be to cause more localised temperature development in a steel frame, though it is not believed that the differences in thermal conductivity between stainless steel and carbon steel has any significant influence on the general fire performance of a structure.

\section{Specific heat}

Specific heat (or specific heat capacity) is the amount of heat per unit mass of a material required to raise the temperature by one degree, and is clearly an important property in controlling the temperature development in a structural member. Figure 5 compares the specific heat of stainless steel and carbon steel at varying temperatures. The figure shows that the specific heat of stainless steel increases steadily with temperature and shows no marked discontinuities (due to the absence of any phase 
change). The specific heat $\mathrm{Ca}_{\mathrm{a}}(\mathrm{J} / \mathrm{kgK})$ of stainless steel may be determined from Equation 1 [12], where $\theta_{a}$ is the temperature $\left({ }^{\circ} \mathrm{C}\right)$.

$$
c_{a}=450+0.280 \theta_{a}-2.91 \times 10^{-4} \theta_{a}{ }^{2}+1.34 \times 10^{-7} \theta_{a}{ }^{3}
$$

The specific heat of carbon steel is, on average, slightly higher than stainless steel, and shows the latent heat of a phase change in the region of $723^{\circ} \mathrm{C}$. On average, the specific heat of carbon steel is approximately $600 \mathrm{~J} / \mathrm{kgK}$, as compared to approximately $550 \mathrm{~J} / \mathrm{kgK}$ for stainless steel. The higher the specific heat of a material, the more slowly it tends to heat up.

\section{Unit mass}

The Euro Inox/SCI Design Manual for Structural Stainless Steel [13] and EN 1993-1-2 [12] state that the unit mass (density) of both carbon steel and stainless steel may be assumed to be independent of temperature and taken as $7850 \mathrm{~kg} / \mathrm{m}^{3}$.

\section{Convective heat transfer coefficient}

The convective heat transfer coefficient is not a material constant, but is known to be a function of the fluid properties, the flow parameters and the geometry of the surface of the heated object [11]. The convective heat transfer coefficient is also a function of temperature, and although convection will occur at all stages of a fire, it is particularly important at low temperatures where radiation levels are low. For use with the standard temperature-time curve, EN 1991-1-2 recommends a single convective heat transfer coefficient $\alpha_{c}$ of $25 \mathrm{~W} / \mathrm{m}^{2} \mathrm{~K}$. In EN 1991-1-2, this value is not dependent on the material, though alternative values are provided for different temperature-time curves (the hydrocarbon curve). In the following sections, the sensitivity of the temperature development in stainless steel cross-sections to variation in the convective heat transfer coefficient $\alpha_{c}$ is assessed numerically; based on experimental and numerical results, a modified value of $\alpha_{c}$ is proposed for use in the temperature development model of EN 1993-1-2 (2005). 


\section{Emissivity (absorptivity)}

Radiative heat transfer is controlled by resultant emissivity. Emissivity is a dimensionless property that ranges between zero and unity, and depends on factors such as temperature, emission angle and wavelength. A common engineering assumption which is adopted in EN 1991-1-2 is that a surface's spectral emissivity does not depend on wavelength, and thus emissivity is taken as a constant. According to Kirchhoff's law of thermal radiation, the emissivity of a surface is also equal to its absorptivity. Thus, an emissivity equal to zero corresponds to all radiation being reflected and an emissivity of unity corresponds to all radiation being absorbed; the lower the emissivity, the more slowly the material heats up.

Tabulated emissivities for materials are widely available in literature, but show substantial variation depending, in particular, on the condition of the surface. In general, the emissivity of a polished metallic surface is very low, whilst the emissivity of dull, oxidised material approaches unity. EN 1993-1-2 adopts an emissivity $\varepsilon \mathrm{m}$ of 0.7 for carbon steel and 0.4 for stainless steel. This study examines the suitability of the adopted emissivity for stainless steel, based on the results of a series of temperature development tests on structural stainless steel sections, and a supporting numerical programme.

The temperature development of a specimen in a furnace depends on both the emissivity of the material $\varepsilon \mathrm{m}$ and the emissivity of the fire (furnace) $\varepsilon \mathrm{f}$, and thus the relative sizes and position of the specimen in the furnace are important [18]. Both of these features are incorporated into resultant emissivity $\varepsilon$ r, which is commonly approximated as the product of the emissivity of the material $\varepsilon m$ and the emissivity of the fire $\varepsilon$. If a specimen is small relative to the dimensions of the furnace and only a negligible amount of emitted radiation is reflected back from the furnace walls, the resultant emissivity will be equal to the emissivity of the material. In EN 1991-1-2 and EN 1993-1-2, the emissivity of the fire is taken in general as unity; in the remainder of the present study, the emissivity of the fire will also be assumed as unity. 


\section{Review of temperature development tests}

All temperature development test data for unprotected austenitic stainless steel sections exposed to fire have been collated. In total, twenty specimens exposed to fire on all four sides and three specimens exposed on three sides (with a concrete slab on the fourth side), have been tested. All specimens were subjected to the standard fire curve defined by ISO 834-1 [16].

Fourteen specimens, tested solely to investigate the temperature development characteristics of stainless steel sections and exposed to fire on all four sides, were reported by Baddoo and Gardner [5]. Other temperature development data were acquired from full scale member tests conducted to determine the fire resistance of structural stainless steel components $[4,5,6,19]$. The deformation of the specimens during testing was assumed not to affect their temperature development.

Tables 1 and 2 summarise the details of the temperature development tests, including section type, nominal dimensions and $A_{m} / V$ ratio. Table 1 contains specimens exposed to fire on all four sides, whilst Table 2 contains specimens exposed to fire on three sides, with a concrete slab on the fourth side.

In all tests, the gas temperature in the furnace was controlled to achieve the standard temperature-time relationship specified in ISO 834-1 [16] and EN 1991-1-2 [17], and given by Equation (2). The relationship of Equation (2) is often referred to as the cellulosic heating rate, and although it does not correspond to an actual fire, it provides a standard basis upon which the fire performance of structural elements may be evaluated.

$$
\theta_{g}=20+345 \log _{10}(8 t+1)
$$

where $\theta_{\mathrm{g}}$ is the gas temperature in the furnace $\left({ }^{\circ} \mathrm{C}\right)$ and $\mathrm{t}$ is the time (minutes).

However, although the furnace temperatures were controlled to follow the standard fire curve, this was not achieved exactly in all cases. Furthermore, even with precise 
control of the furnace, there are still some factors such as differences in furnace construction, fuel used and mode of operation that can cause variation in the effective heat flux at the surface of the test specimen [20].

\section{Numerical modelling}

\section{Background}

Numerical models, using the general purpose finite element package ABAQUS [21], were developed in order to simulate the temperature development of the test specimens. Initially, values for the heat transfer coefficient and emissivity were taken as those recommended in EN 1991-1-2 and EN 1993-1-2. Parametric studies were subsequently carried out to investigate the suitability of these values.

The heat transfer analyses adopted in this study utilise heat conduction with general, temperature dependent conductivity, internal energy (including latent heat effects where appropriate), and general convection and radiation boundary conditions. The analyses do not consider the stress or deformation of the member; instead only the temperature field is calculated. However the analyses are non-linear because the material properties are temperature dependent, though the non-linearity is mild because the properties do not change rapidly with temperature [22]. A number of previous studies have demonstrated the applicability of ABAQUS to the modelling heat transfer problems in structural fire engineering $[23,24]$.

\section{Development of models}

Temperature development is controlled by combined convective and radiative heat transfer. The net heat flux $\dot{\mathrm{h}}_{\text {net }}\left(\mathrm{W} / \mathrm{m}^{2}\right)$ is therefore given as the sum of the heat flux due to convection $\dot{\mathrm{h}}_{\text {net,c }}$ (Equation 3) and that due to radiation $\dot{\mathrm{h}}_{\mathrm{net}, \mathrm{r}}$ (Equation 4).

$$
\dot{\mathrm{h}}_{\mathrm{net}, \mathrm{c}}=\alpha_{\mathrm{c}}\left(\theta_{\mathrm{g}}-\theta_{\mathrm{m}}\right)
$$


where $\dot{\mathrm{h}}_{\text {net,c }}$ is the net convective heat flux $\left(\mathrm{W} / \mathrm{m}^{2}\right), \alpha_{c}$ is the convective heat transfer coefficient, $\theta_{\mathrm{g}}$ is the gas temperature in the furnace $\left({ }^{\circ} \mathrm{C}\right)$ and $\theta_{\mathrm{m}}$ is the surface temperature of the member $\left({ }^{\circ} \mathrm{C}\right)$.

$$
\dot{\mathrm{h}}_{\text {net, } \mathrm{r}}=\Phi \varepsilon_{\mathrm{m}} \varepsilon_{\mathrm{f}} \sigma\left[\left(\theta_{\mathrm{r}}+273\right)^{4}-\left(\theta_{\mathrm{m}}+273\right)^{4}\right]
$$

where $\dot{h}_{n e t, r}$ is the net radiative heat flux $\left(W / m^{2}\right), \Phi$ is the configuration factor (generally taken as unity), $\varepsilon_{\mathrm{m}}$ is the emissivity of the material, $\varepsilon_{\mathrm{f}}$ is the emissivity of the fire, $\sigma$ is the Stefan-Boltzmann constant $\left(=5.67 \times 10^{-8} \mathrm{~W} / \mathrm{m}^{2} \mathrm{~K}^{4}\right), \quad \theta_{\mathrm{r}}$ is the effective radiation temperature of the fire $\left({ }^{\circ} \mathrm{C}\right)$ and $\theta \mathrm{m}$ is the surface temperature of the member $\left({ }^{\circ} \mathrm{C}\right)$.

Thermal conductivity and specific heat are both temperature dependent. For this study, their values have been determined from EN 1993-1-2 [12], and are as given in Figures 4 and 5 . The density of stainless steel may be considered to be independent of temperature and has been taken as $\rho_{a}=7850 \mathrm{~kg} / \mathrm{m}^{3}$. The heat transfer analyses do not consider deformation of the sections, thus material stress-strain properties are not required. The heat transfer shell elements DS4 were adopted throughout the study [21].

\section{Specimens exposed to measured furnace temperature on all four sides}

The temperature development of each of the twenty tests outlined in Table 1 was modelled numerically, adopting the heat transfer coefficient proposed in EN 1991-1-2 $\left(\alpha_{c}=25 \mathrm{~W} / \mathrm{m}^{2} \mathrm{~K}\right)$, the emissivity proposed in EN 1993-1-2 $(\varepsilon \mathrm{m}=0.4)$ and the measured furnace temperature-time relationships. A sample of the finite element models are shown in Figure 6, and comparisons between test and finite element results are made in Figure 7 . The measured furnace temperature-time curves were initially adopted in the finite element models in preference to that specified in ISO 834-1 (Equation 2), to minimise disparities between test and model behaviour due to differences in the basic fire curve. The comparisons of Figures $7(\mathrm{~h})$ and $7(\mathrm{k})$ indicate the validity of this proposal, where the rapid increase in steel temperature observed in the test at around 
$850^{\circ} \mathrm{C}$ in response to a sharp increase in furnace temperature was also picked up by the finite element model.

Comparisons between test and FE results for each of the twenty specimens exposed to fire on all four sides are shown in Figures $7(\mathrm{a})$ to $7(\mathrm{t})$. In these finite element models, the measured furnace temperatures were applied directly to the surfaces of the models, and no account was made for shadow effects. The shadow effect refers to the reduced heat flux that inner surfaces of flanged sections receive due to their partial obscurity from the direct action of the fire. Cross-sections with a convex profile (such as structural hollow sections) are therefore not subject to such effects. It is not straightforward to incorporate shadow effects directly into finite element models because of the uncertainty in specifying suitable reduced values for emissivity and the heat transfer coefficient in the partially obscured areas of the sections. It was therefore decided to allow for shadow effects indirectly by modifying the finite element results by means of the correction factor $\mathrm{ksh}_{\mathrm{sh}}$ which is included in the calculation model (Equation 7) set out in EN 1993-1-2. The finite element temperatures were reduced by a proportion obtained from the calculation model temperatures determined with and without shadow effects. The correction factor $\mathrm{k}_{\mathrm{sh}}$ introduces the concept of a box value for the section factor $\left[A_{m} / V\right]_{b}$ defined as the ratio between the exposed surface area of a notional bounding box to the section and the volume of steel [12], and may be determined from Equation 5 for an I-section and from Equation 6 in all other cases. Comparison between test and modified FE results with shadow effects is shown in Table 3.

$$
\begin{aligned}
& \mathrm{k}_{\mathrm{sh}}=0.9\left[\mathrm{~A}_{\mathrm{m}} / \mathrm{V}\right]_{\mathrm{b}} /\left[\mathrm{A}_{\mathrm{m}} / \mathrm{V}\right] \\
& \mathrm{k}_{\mathrm{sh}}=\left[\mathrm{A}_{\mathrm{m}} / \mathrm{V}\right]_{\mathrm{b}} /\left[\mathrm{A}_{\mathrm{m}} / \mathrm{V}\right]
\end{aligned}
$$

where $\left[A_{m} / V\right]_{b}$ is the box value for the section factor defined above and $\left[A_{m} / V\right]$ is the familiar section factor. The closer the box value of the section factor to the general section factor, the lesser the influence of the shadow effect - consequently, for hollow sections, the correction factor for the shadow effect $k_{s h}$ equals unity. Values of $k_{s h}$ for the twenty tested (and modelled) sections have been included in Table 1. Figure 8 
demonstrates the significance of the shadow effect on temperature development for varying $k_{s h}$ and varying $A_{m} / V$ at 20 minutes exposure time to ISO 834-1. The graph shows that, in general, the shadow effect is relatively small (given typical values of ksh and $A_{m} / V$, such as those in Table 1 ), but becomes more significant at low values $A_{m} / V$.

Table 3 compares the results of the modified finite element analyses including shadow effects (taking $\varepsilon_{m}=0.4$ and $\alpha_{c}=25 \mathrm{~W} / \mathrm{m}^{2} \mathrm{~K}$ ) with those from the tests. The results show that the temperature development is over-predicted for all fire exposure times (between 10 minutes and 60 minutes) using the recommended values for $\varepsilon \mathrm{m}$ and $\alpha_{c}$. Ignoring shadow effects led to a slightly greater over-prediction. A parametric study is conducted in the following section with the aim of investigating the sensitivity of temperature development in stainless steel sections to variation in $\varepsilon_{m}$ and $\alpha_{c}$ and of identifying more appropriate values. It should be noted that the influence of the shadow effect on the results was very small, but it has been included to ensure that conservative values of $\varepsilon \mathrm{m}$ and $\alpha_{c}$ were derived.

\section{Specimens exposed to measured furnace temperature on three sides (beams)}

The temperature development of the three beam tests outlined in Table 2 (where the specimens were exposed to fire on three sides, with on concrete slab on the fourth) was modelled numerically, also adopting the heat transfer coefficient proposed in EN 19911-2 $\left(\alpha_{c}=25 \mathrm{~W} / \mathrm{m}^{2} \mathrm{~K}\right)$, the emissivity proposed in EN 1993-1-2 $\left(\varepsilon_{\mathrm{m}}=0.4\right)$ and the measured furnace temperature-time relationships. Thermal actions were not applied to the top side of the upper flanges, which were protected by the concrete slab. Initially, no account was made for shadow effects or for the heat sink effect of the concrete slab.

In all three beam tests, thermocouples were peened into the surface of the specimens to measure the temperature development around the cross-section and along the length of the members. Temperatures were relatively uniform along the lengths of the member, but displayed more significant variation around the cross-sections. The positions of the thermocouples around the cross-sections and the corresponding measured temperature-time relationships are shown in Figures 9 to 11. 
As anticipated, with no account for shadow effects or for the heat sink effect of the concrete slab, the observed temperature rises in the lower flanges of the beams were well predicted numerically, but there is less good correlation for other parts of the crosssection, particularly towards the concrete slab. In the following section, parametric studies are performed on the three stainless steel beams to improve the correlation between finite element and test behaviour.

\section{Parametric numerical studies}

\section{Specimens exposed to fire on all four sides}

In this section, the sensitivity of the models to variation in heat transfer coefficient and emissivity is assessed. As an illustration of sensitivity, Figures 12 and 13 show numerically generated temperature-time curves for the RHS $150 \times 75 \times 6\left(A_{m} / \mathrm{V}=168.2 \mathrm{~m}^{-}\right.$

$\left.{ }^{1}\right)$ with varying values of heat transfer coefficient and emissivity. In Figure 12, emissivity is held constant $\left(\varepsilon_{\mathrm{m}}=0.4\right)$ and the heat transfer coefficient is varied between $\alpha_{c}=1$ $\mathrm{W} / \mathrm{m}^{2} \mathrm{~K}$ and $\alpha_{c}=40 \mathrm{~W} / \mathrm{m}^{2} \mathrm{~K}$. In Figure 13 , the heat transfer coefficient is held constant $\left(\alpha_{c}=25 \mathrm{~W} / \mathrm{m}^{2} \mathrm{~K}\right)$ and emissivity is varied between 0.1 and 0.4 . The figures demonstrate, as expected, that lower values of both heat transfer coefficient and emissivity lead to slower temperature development, and that heat transfer by convection (controlled by the heat transfer coefficient) is more significant at low temperatures, whereas heat transfer by radiation (controlled by emissivity) is dominant at higher temperatures.

Figures 14 to 16 compare all test results with numerical predictions of varying heat transfer coefficient and emissivity. On the vertical axes, the temperature predicted by the FE model is divided by the temperature recorded in the test; thus a factor greater than unity indicates that the model is heating up more rapidly than the test. In general, it may be seen that temperature development is most sensitive to variation in both the heat transfer coefficient and emissivity at short exposure times - less than about 30 minutes - (i.e. at low temperatures). It may also be observed that the proposed codified values $\left(\varepsilon_{\mathrm{m}}=0.4\right.$ and $\left.\alpha_{c}=25 \mathrm{~W} / \mathrm{m}^{2} \mathrm{~K}\right)$ result in a consistent over-prediction of the rate of 
temperature development; this is confirmed in Table 3 where comparisons for the individual test specimens are given.

Tables 4 to 6 present the mean predicted (FE) divided by test temperatures for the twenty test specimens at ten minute intervals of fire exposure time, along with the corresponding coefficient of variation of the predictions. The parametric studies show that the temperature development of structural stainless steel sections exposed to fire on all four sides is best predicted by taking emissivity $\varepsilon \mathrm{m}=0.2$ and the heat transfer coefficient $\alpha_{c}=35 \mathrm{~W} / \mathrm{m}^{2} \mathrm{~K}$. These values produce a predicted-to-test temperature ratio of unity and exhibit the minimum of scatter, and it is therefore proposed that these be adopted in place of those currently recommended in EN 1991-1-2 and EN 1993-1-2. The influence of adopting the proposed coefficients on the fire resistance of structural members is assessed in a following section.

\section{Specimens exposed to fire on three sides}

The temperature development in three stainless steel beams exposed to fire on three sides and supporting a concrete slab on the fourth was recorded experimentally, as described in the previous section, and initially modelled numerically ignoring shadow effects and the heat sink effect of the concrete. Large discrepancies between test and model behaviour indicated the importance of the influence of the concrete slab.

Modelling of the heat transfer between a structural steel section and an adjoining concrete slab and indeed within the concrete slab itself is complex, because of the large number of uncertainties that exist. These include details of the interface between the materials, the conductivity, density and specific heat of the concrete slab, the moisture content of the concrete and values of emissivity and heat transfer coefficients. Given the scarcity in test results on stainless steel beams supporting concrete slabs, and uncertainties in many of the above parameters, it was not deemed appropriate to conduct an extensive numerical analysis of the beam tests. Detailed numerical heat transfer analyses of composite slabs in fire, including thorough parametric studies have been performed by Lamont et al. [25]. Nonetheless, improved correlation between the 
test results and numerical results was sought using assumed values for the required parameters.

The density of the concrete slabs in the three tests was calculated based on the reported self-weights and nominal dimensions [5] to be approximately $2000 \mathrm{~kg} / \mathrm{m}^{3}$. The thermal conductivity and specific heat of the concrete slab were assumed to be 0.7 $\mathrm{W} / \mathrm{mK}$ and $700 \mathrm{~J} / \mathrm{kgK}$, respectively, based on values adopted by Lamont et al. [25]. The heat transfer coefficients for the top and bottom of the concrete slab were taken as 10 and $5 \mathrm{~W} / \mathrm{m}^{2} \mathrm{~K}$, respectively, whilst the emissivity of the concrete was taken as 0.6 , all based on the reference values of Lamont et al. [25]. Values for the emissivity and heat transfer coefficient for the fully exposed lower flanges of the beams, and the webs of the RHS beam, were taken as those generated in the present study for stainless steel sections exposed to fire on all four sides $\left(\varepsilon m=0.2\right.$ and $\left.\alpha_{c}=35 \mathrm{~W} / \mathrm{m}^{2} \mathrm{~K}\right)$. For the partially obscured web and upper flange of the I-sections beams, values of emissivity and heat transfer were adjusted in order to improve the fit with test results, a technique adopted by Wang [22]. Reasonable agreement was achieved with the adoption of the values given in Table 7, as shown in Figures 17 to 19.

Despite reasonable agreement between finite element and test behaviour, the results of the beam analyses are not included in the determination of suitable values for emissivity and the heat transfer coefficient, due primarily to the uncertainties surrounding the properties of the concrete slab and the limited number of test results. The influence of a concrete slab on the temperature development of a structural stainless steel section would not be expected to be significantly different to its influence on a carbon steel section. It is therefore considered that the carbon steel current practice of employing the adaptation factor $\kappa_{1}$ to allow for non-uniform temperature in the calculation of member resistances may be equally applicable to stainless steel beams supporting a concrete or composite slab. 


\section{Calculation model}

Temperature development in unprotected and uniformly heated steelwork is determined in EN 1993-1-2 [12] using the simple calculation model of Equation 7, in which $\Delta \theta a, t$ is the increase in temperature $\left({ }^{\circ} \mathrm{C}\right)$ in a time increment $\Delta \mathrm{t}$ (in seconds).

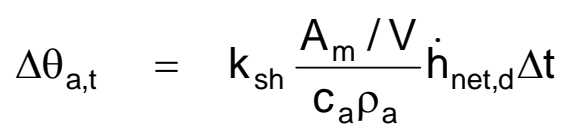

where $k_{s h}$ is the correction factor for the shadow effect, $A_{m} / V$ is the section factor $\left(m^{-1}\right)$, $\mathrm{C}_{\mathrm{a}}$ is the specific heat of the material, $\rho_{a}$ is the material density $\left(\mathrm{kg} / \mathrm{m}^{3}\right)$, and $\dot{\mathrm{h}}_{\mathrm{net}, \mathrm{d}}$ is the design value of the net heat flux per unit area $\left(\mathrm{W} / \mathrm{m}^{2} \mathrm{~K}\right)$.

Calibration of the calculation model (i.e. selection of suitable values for emissivity and the heat transfer coefficient to determine the net heat flux) for structural carbon steel was originally conducted during the development of ENV 1991-1-2 [18] and was reevaluated for the conversion to EN 1991-1-2 [26]. The calculation model would not be expected to yield exactly the same results as the FE model because of the simplification of using the $A m / V$ ratio to represent the profile of the section, and assuming uniform temperature throughout the section (despite elements of different form and thickness). However, for common geometries the errors will be very small.

It is difficult to validate the calculation model directly against the tests, because the furnace temperatures did not always exactly follow the standard fire curve, and the measured furnace temperature cannot be used easily in the calculation model because there is no simple formulation to describe the measured furnace temperature, as there is with ISO 834-1 (Equation 2). However, having validated the numerical model against the test data, it is possible to compare the calculation model against the test results where the measured furnace temperature closely followed ISO 834-1 and against finite element results generated with the ISO 834-1 fire curve. An example of this comparison, using the proposed values for emissivity $\left(\varepsilon_{\mathrm{m}}=0.2\right)$ and the heat transfer coefficient $\left(\alpha_{c}=35 \mathrm{~W} / \mathrm{m}^{2} \mathrm{~K}\right)$ is shown in Figure 20. The resultant temperature-time curves from the finite element model and the calculation model coincide. 


\section{Influence of modified coefficients on fire resistance of structural members}

Based on comparisons with all available test data, revised values for the heat transfer coefficient and emissivity of structural stainless steel sections have been proposed. Figure 21 compares the temperature development in a structural section $\left(A_{m} / V=200 \mathrm{~m}\right.$ $\left.{ }^{1}\right)$ made of stainless steel (with the current and proposed values for the emissivity and heat transfer coefficient) and of carbon steel. For carbon steel, the emissivity and heat transfer coefficient were taken as 0.7 (as recommended by EN 1993-1-2) and 25 $\mathrm{W} / \mathrm{m}^{2} \mathrm{~K}$ (as recommended by EN 1991-1-2), respectively, and the mechanical and thermal properties were taken as described previously in this paper. The two curves were generated using the calculation model of Equation 7. The comparison shows the effect of the proposed values for emissivity and the heat transfer coefficient on the temperature development in structural stainless steel sections, and indicated generally that a stainless steel section heats up slightly less rapidly than a similar carbon steel section.

In the remainder of this section, the significance of the proposed modified values for emissivity and the heat transfer coefficient on the fire resistance of structural members is assessed. The critical temperature and fire resistance of six stainless steel columns $[5,6]$ are predicted using the design method of EN 1993-1-2, adopting the emissivity and the heat transfer coefficient recommended in the Code, and those proposed in the present study. The results are given in Table 8, and demonstrate that for all of the members considered, use of the proposed coefficients yields improved predictions of test performance. Critical temperatures vary with the use of different values for emissivity and the heat transfer coefficient simply because of the requirement to present fire resistance to the nearest minute. Average enhancements in fire resistance of $10 \%$ are achieved.

The relative strength and stiffness of the material are key in defining the response of a structural member (i.e. whether it is more prone to buckling or yielding). In ENV 1993-12 (2001) [27], the $\varepsilon$ factor used in section classification limits and in the determination of effective section properties was modified at fire limit state to reflect that loss of strength 
and stiffness at elevated temperatures does not occur at the same rate. Thus, at elevated temperatures $\varepsilon$ was modified by the factor $\left(\mathrm{K}_{\mathrm{E}, \theta} / \mathrm{k}_{\mathrm{y}, \theta}\right)^{0.5}$ and defined by Equation 8.

$$
\varepsilon=\left[\left(\frac{235}{f_{y}}\right)\left(\frac{k_{E, \theta}}{k_{y, \theta}}\right)\right]^{0.5}
$$

where $f_{y}$ is the room temperature material yield strength, $k_{y, \theta}$ is the strength reduction factor defined as the elevated temperature strength at $2 \%$ total strain $f_{2 \%, \theta}$, normalised by the room temperature $0.2 \%$ proof strength $f_{0.2 \%}$, and $k_{E, \theta}$ is the stiffness reduction factor defined as the elevated temperature initial tangent modulus $E_{\theta}$, normalised by the initial tangent modulus at room temperature $\mathrm{E}$.

Variation of the modification factor $\left(\mathrm{k}_{\mathrm{E}, \theta} / \mathrm{k}_{\mathrm{y}, \theta}\right)^{0.5}$ with temperature for carbon steel and stainless steel is shown in Figure 22, where a value less than unity represents greater susceptibility to buckling. From Figure 22, it may be seen that for the majority of the elevated temperature range, carbon steel is more susceptible to buckling (as opposed to yielding) than at room temperature, and neglecting this feature leads to unsafe predictions. To simplify calculations, this factor was set as a constant of 0.85 (which was deemed an acceptably safe average value at fire limit state) in EN 1993-1-2, for both carbon steel and stainless steel. However, clearly, from Figure 22, this factor is unjustified for stainless steel and cross-section classification based on room temperature design remains acceptable for fire design. In fact, modification factors greater than unity may be acceptable at elevated temperatures, but this requires further investigation; such investigations are currently underway.

\section{Conclusions}

Stainless steel is gaining increasing usage in the construction industry following heightened research activity and the subsequent development and publication of 
structural design guidance. Despite the high initial material cost associated with stainless steel, a number of areas of benefit have been identified that may partially or completely offset any economic disparities with traditional materials when projects are viewed on a holistic basis. Fire resistance is one such area where stainless steel offers superior performance to structural carbon steel.

In this paper the mechanical and thermal properties of stainless steel and carbon steel have been compared, and the significance of the differences explored. The strength and stiffness retention of austenitic stainless steel at elevated temperatures is superior to that of carbon steel, though it should be noted that stainless steel also exhibits a higher level of thermal expansion. The consequence of higher thermal expansion will depend on structural usage, but it is clear that more severe loading will result in axially restrained stainless steel members.

Whether fire resistant design is based on a prescriptive approach or a performance based approach, or indeed whether isolated elements or complete structural assemblages are considered, accurate and efficient determination of the temperature development within a structural member upon subjection to fire is paramount. The physical properties of stainless steel that influence temperature development have been discussed and the suitability of the emissivity and heat transfer coefficient currently recommended in the structural Eurocodes have been examined. Following analysis of all available test data on structural stainless steel sections and numerically generated results, revised values for the emissivity and heat transfer coefficient of structural stainless steel members exposed to fire are proposed. In the temperature development calculation model of EN 1993-1-2, it is proposed that emissivity be taken as 0.2 (in place of 0.4 ) and the heat transfer coefficient be taken as $35 \mathrm{~W} / \mathrm{m}^{2} \mathrm{~K}$ (in place of 25 $\left.\mathrm{W} / \mathrm{m}^{2} \mathrm{~K}\right)$. This achieves better correlation between predicted and measured temperature development in structural stainless steel sections and results in average enhancements of $10 \%$ in fire resistance. 


\section{Acknowledgements}

The authors would like to thank the Lee Foundation for contributing to the funding of this project, and the Steel Construction Institute for technical input.

\section{References}

[1] Bailey, C. (2004). Structural fire design: Core or specialist subject? The Structural Engineer, 82(9), pp. 32-38.

[2] Wong, M. B., Ghojel, J. I., and Crozier, D. A. (1998). Temperature-time analysis for steel structures under fire conditions. International Journal of Structural Engineering and Mechanics, 6(3), 275-289.

[3] Ala-Outinen, T. and Oksanen, T. (1997) Stainless steel compression members exposed to fire. VTT Research Notes 1864, Espoo, Finland

[4] Baddoo, N. R. and Burgan, B. A. (1998). Fire resistance design of austenitic stainless steel. Paper No. 243. Second World Conference on Steel Structures, San Sebastian. May 1998.

[5] Baddoo, N. R. and Gardner, L. (2000). Member behaviour at elevated temperatures: Work package 5.2. ECSC project 'Development of the use of stainless steel in construction'. Contract No. 7210 SA/842. The Steel Construction Institute, UK.

[6] Gardner, L. and Baddoo, N. R. (submitted). Fire testing and design of stainless steel structures. Journal of Constructional Steel Research.

[7] Wang, Y. C. (2000). An analysis of the global structural behaviour of the Cardington steelframed building during the two BRE fire tests. Engineering Structures. 22(5), 401-412.

[8] Wang, Y. C. (1998). Composite beams with partial fire protection. Fire Safety Journal. 30(4), 315-332. 
[9] Parker, A.J., Beitel, J.J., and Iwankiw, N.R. (2005). Fire Protection Materials for Architecturally Exposed Structural Steel (AESS). Structure Magazine, National Council of Structural Engineers Association. February 2005, pp 33-36.

[10] Gardner, L. (2005). The use of stainless steel in structures. Progress in Structural Engineering and Materials. 7(2). 45-55.

[11] Drysdale, D. (1985). An introduction to fire dynamics. Second edition. John Wiley and Sons Ltd.

[12] EN 1993-1-2. (2005). Eurocode 3: Design of steel structures - Part 1.2: General rules Structural fire design. CEN.

[13] Design Manual for Structural Stainless Steel. (2002). Second edition. Euro Inox and the Steel Construction Institute. Building series, Volume 3.

[14] EN 10088-1. (1995). Stainless steels - Part 1: List of stainless steels. CEN.

[15] EN 10088-2. (1995). Stainless steels - Part 2: Technical delivery conditions for sheet/plate and strip for general purposes. CEN.

[16] ISO 834-1. (1999). Fire-resistance tests - Elements of building construction - Part 1: General requirements. International Organization for Standardization, Geneva.

[17] EN 1991-1-2. (2002). Eurocode 1: Actions on structures - Part 1.2: General actions Actions on structures exposed to fire. CEN.

[18] Kay, T. R., Kirby, B. R., and Preston, R. R. (1996). Calculation of the heating rate of an unprotected steel member in a standard fire resistance test. Fire Safety Journal, 26(4), 327-350.

[19] Ala-Outinen, T. (1999). Fire resistance of stainless steel structures. Proceedings of the Second European Conference on Steel Structures (Eurosteel 1999). Prague, Czech Republic, 26th-29th May, 1999. 165-168.

[20] Thomson, G. and Preston R. R. (1996). Towards harmonised standard fire resistance testing. Fire Safety Journal, 27(2), 91-112. 
[21] ABAQUS (2003). ABAQUS/ Standard User's Manual Volumes I-III and ABAQUS CAE Manual. Version 6.4. Hibbitt, Karlsson \& Sorensen, Inc. Pawtucket, USA.

[22] Wang, H. B. (1995). Heat Transfer Analysis of Components of Construction Exposed to Fire. PhD Thesis. Department of Civil Engineering and Construction, University of Salford, Manchester.

[23] Feng, M., Wang, Y. C. and Davies J. M. (2003), Thermal performance of cold-formed thinwalled steel panel systems in fire. Fire Safety Journal. 38(4), 365-394.

[24] Yin, Y. Z. and Wang, Y. C. (2004). A numerical study of large deflection behaviour of restrained steel beams at elevated temperatures. Journal of Constructional Steel Research. 60(7), 1029-1047.

[25] Lamont, S., Usmani, A.S. and Drysdale, D.D. (2001). Heat transfer analysis of the composite slab in the Cardington frame fire tests. Fire safety journal. $\mathbf{3 6 ( 8 ) , ~ 8 1 5 - 8 3 9 . ~}$

[26] Kirby, B. (2004). Calibration of Eurocode 1: actions on structures - Part 1.2: actions on structures exposed to fire. The Structural Engineer. 82(19), 38-43.

[27] ENV 1993-1-2. (2001). Eurocode 3: Design of steel structures - Part 1.2: General rules Structural fire design. CEN. 


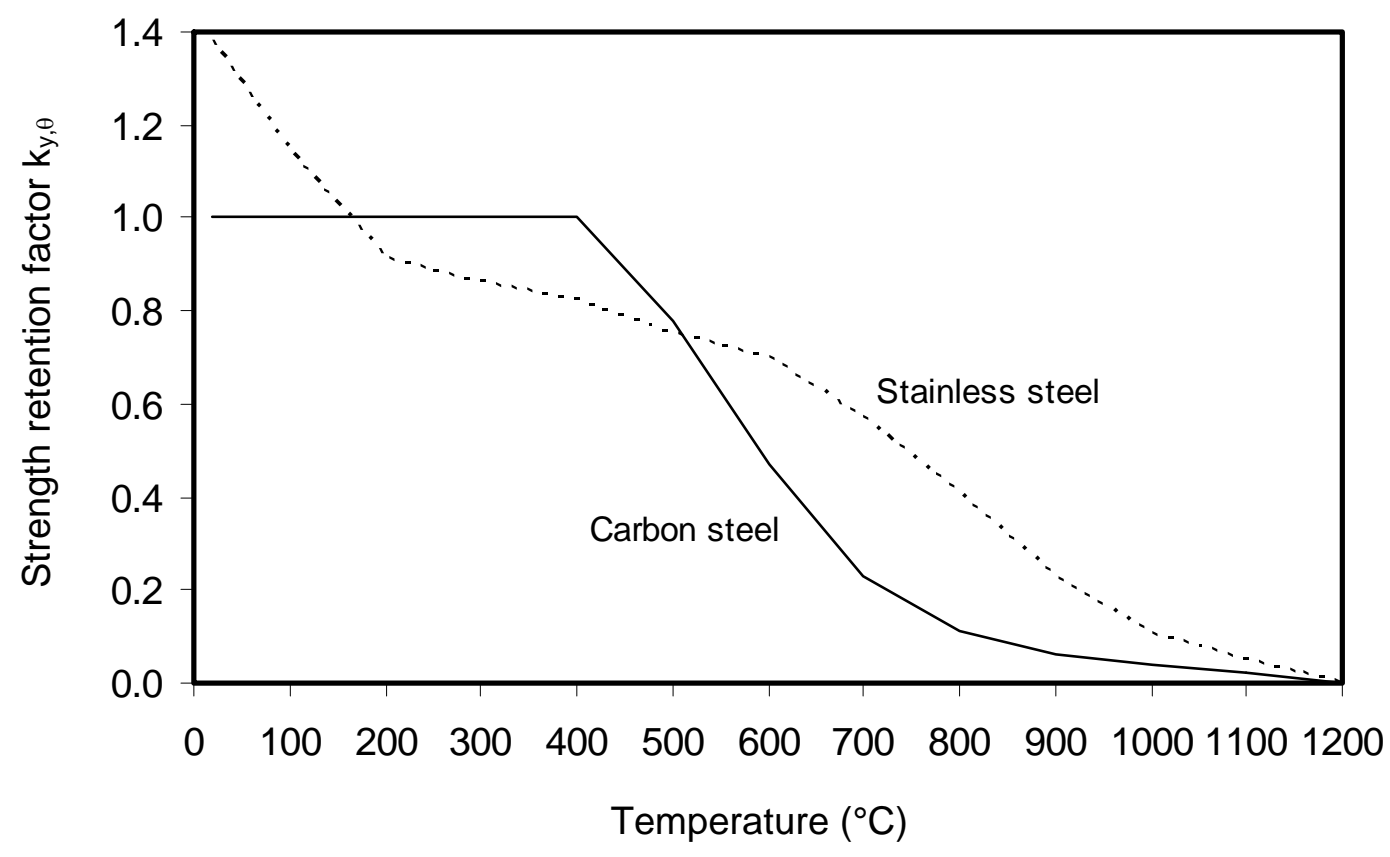

Figure 1: Comparison of strength reduction at elevated temperatures 


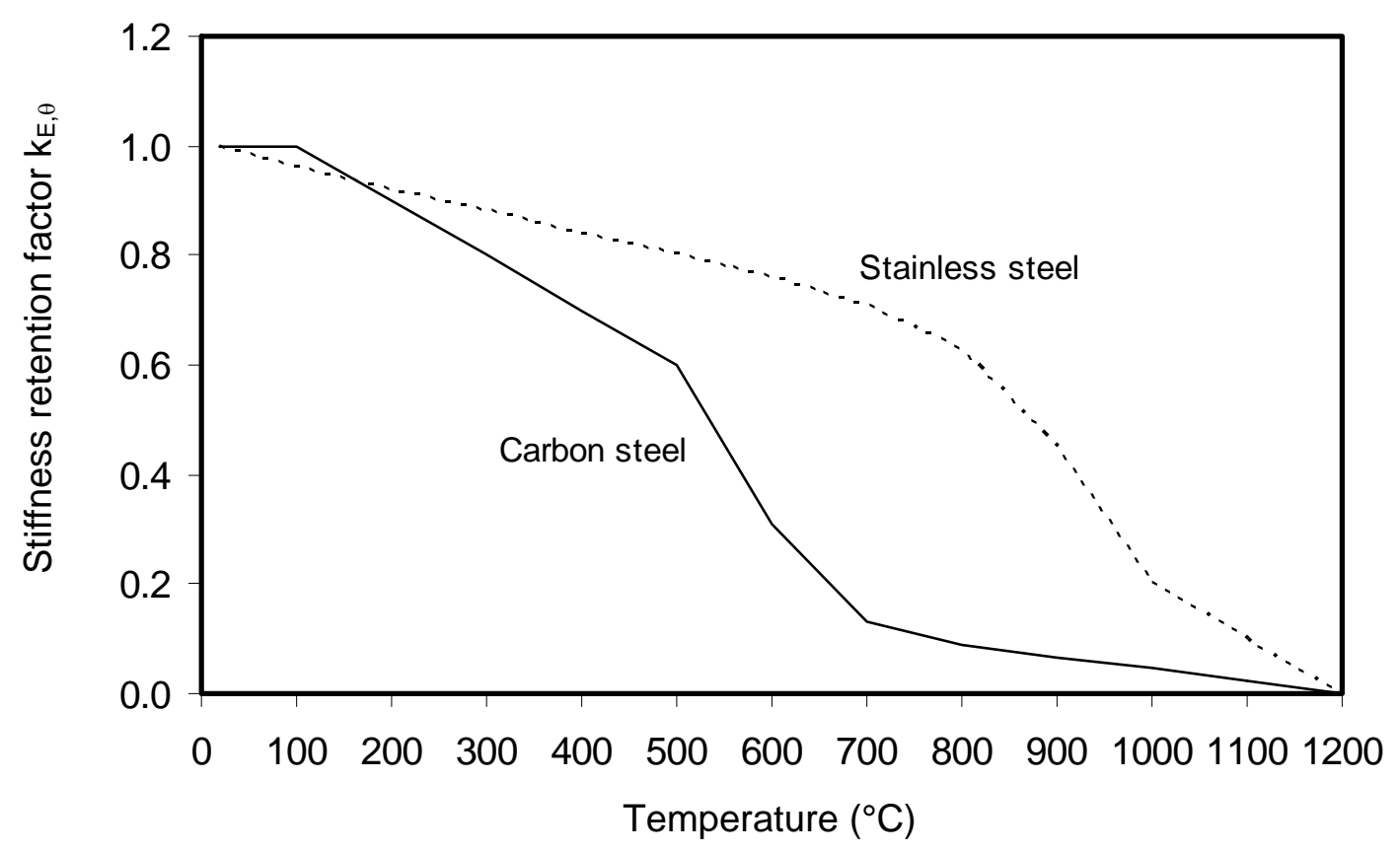

Figure 2: Comparison of stiffness reduction at elevated temperatures 


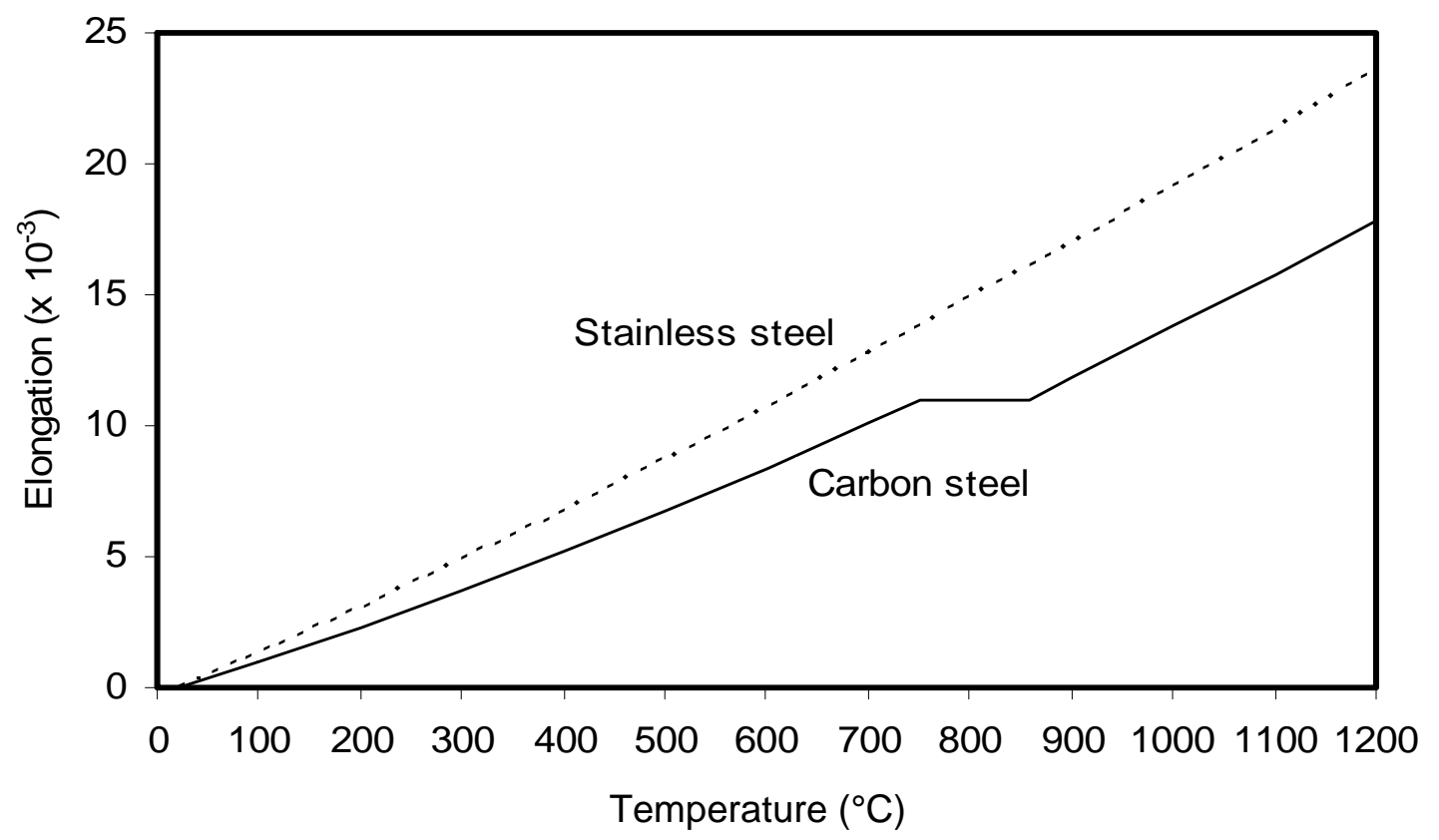

Figure 3: Thermal elongation of carbon steel and stainless steel 


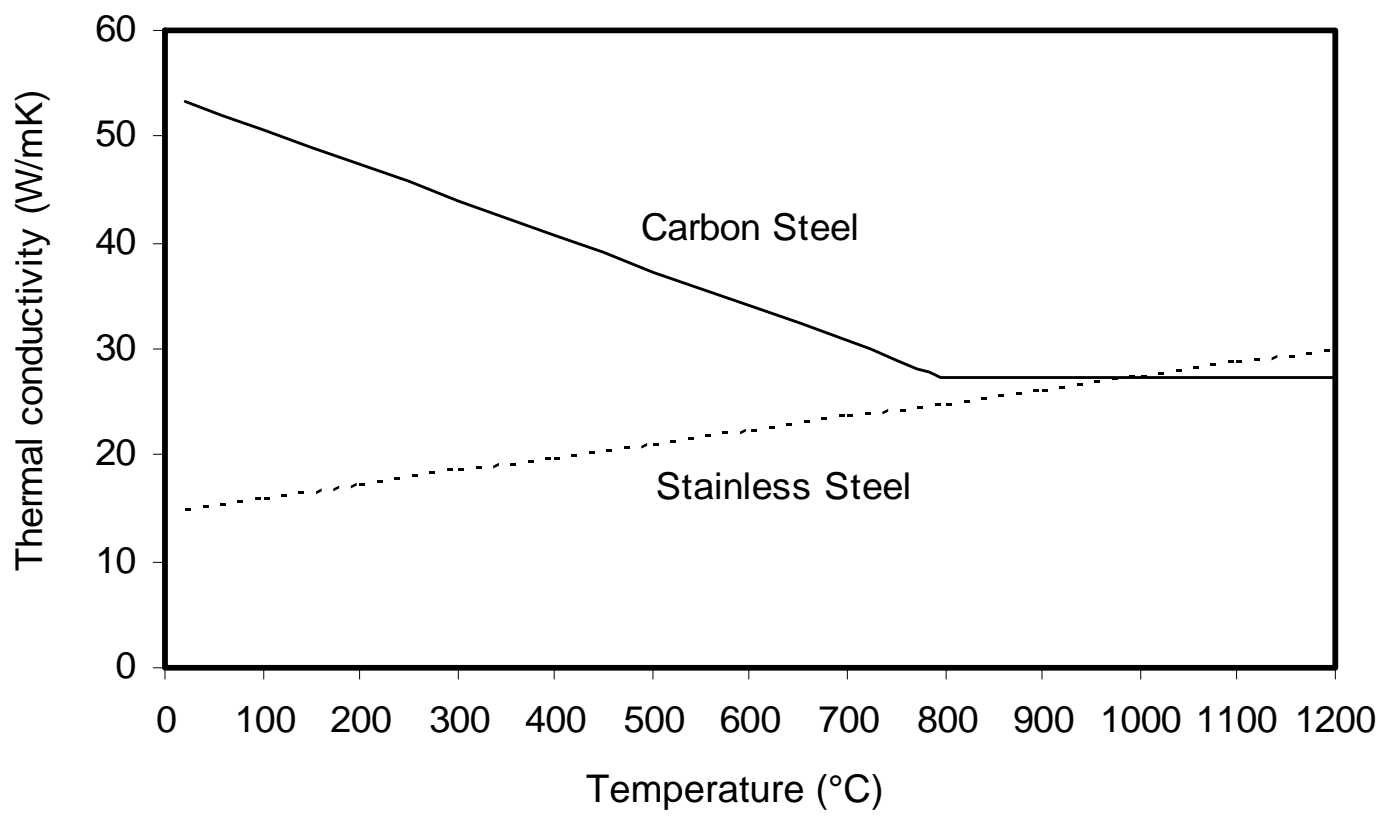

Figure 4: Thermal conductivity of carbon steel and stainless steel 


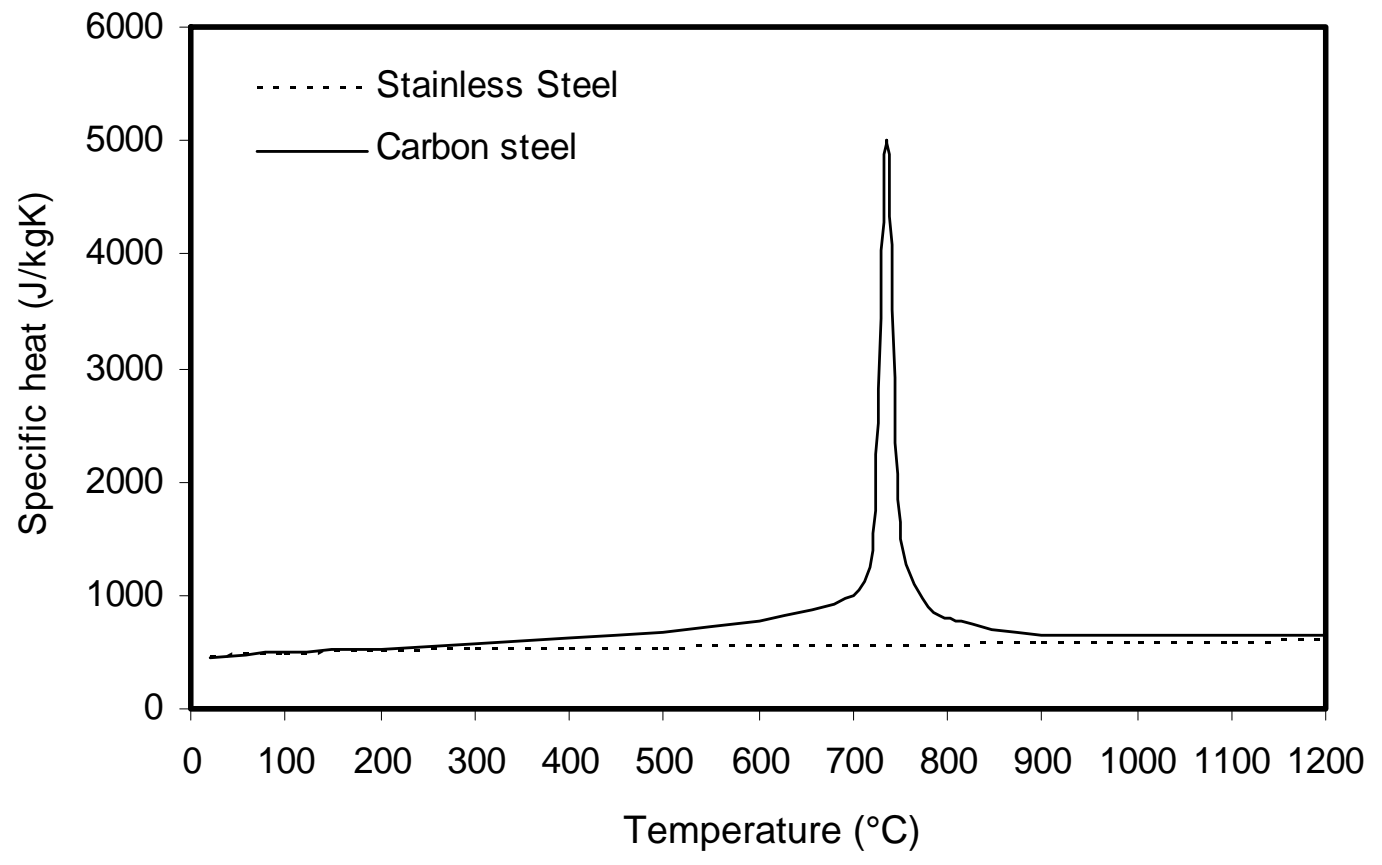

Figure 5: Specific heat of carbon steel and stainless steel 

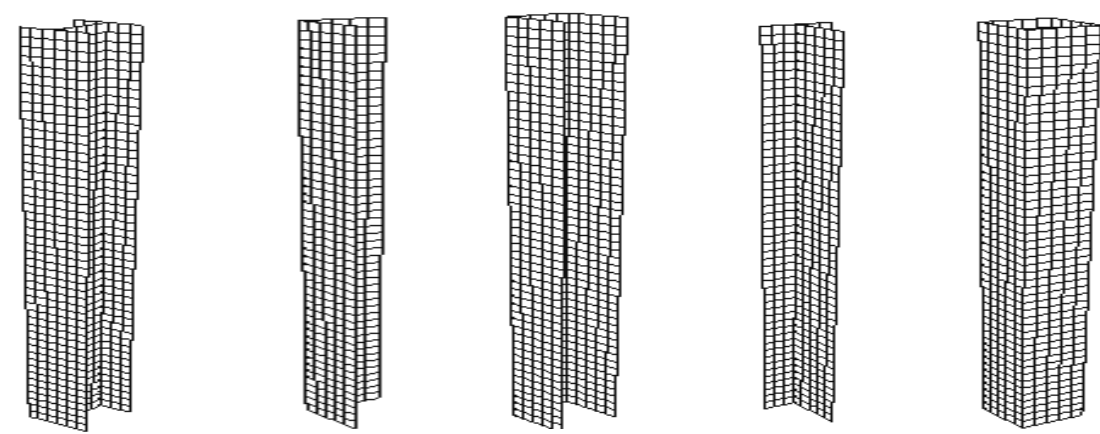

Figure 6: Sample of finite element models 


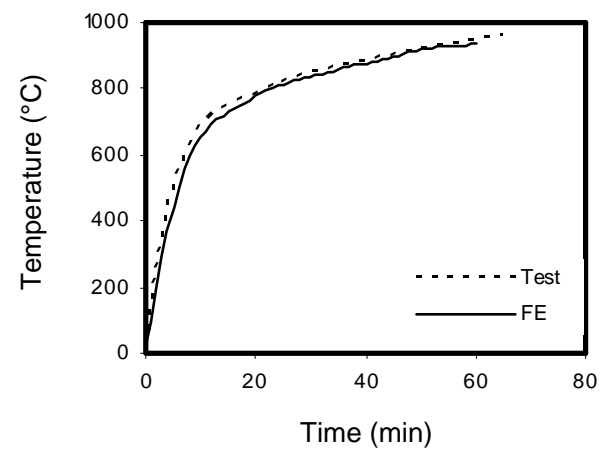

(a): $L 20 \times 20$

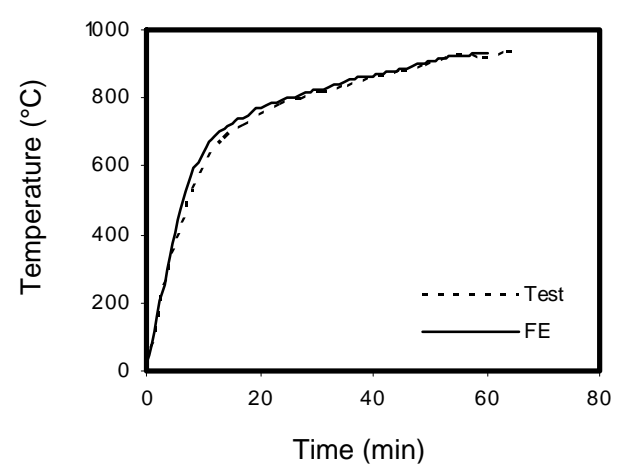

(c): $130 \times 15$

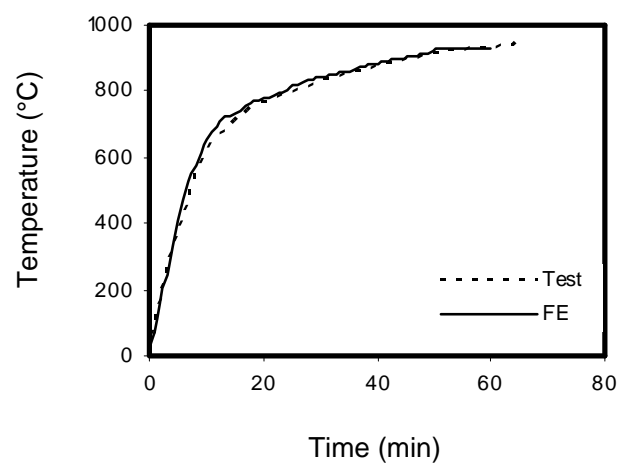

(e): $T 25 \times 25$

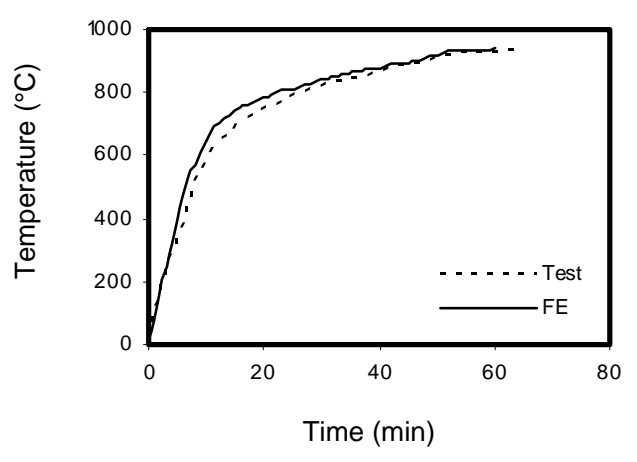

(g): $180 \times 40$

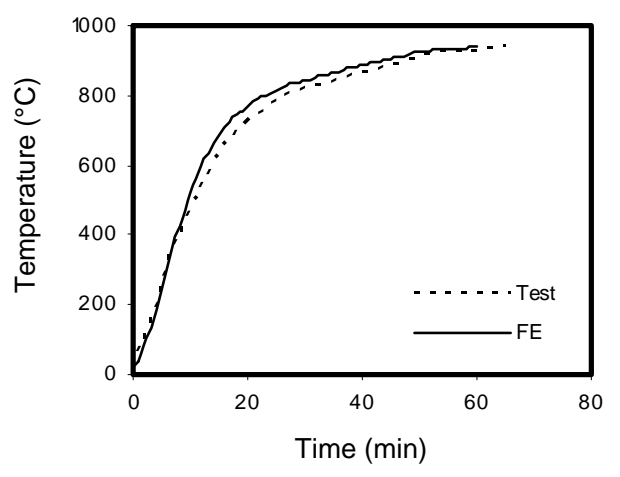

(b): $L 100 \times 100$

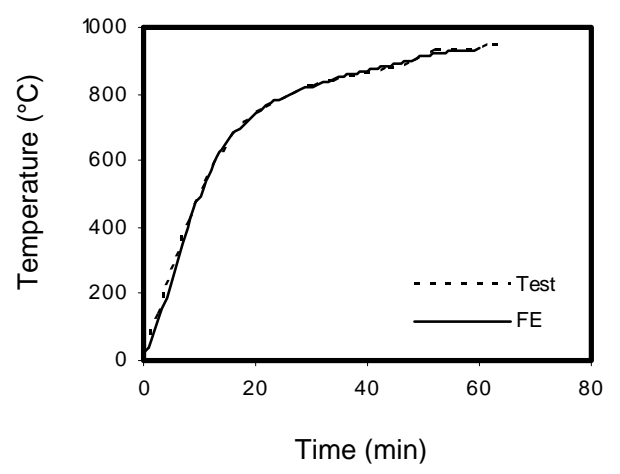

(d): U160×65
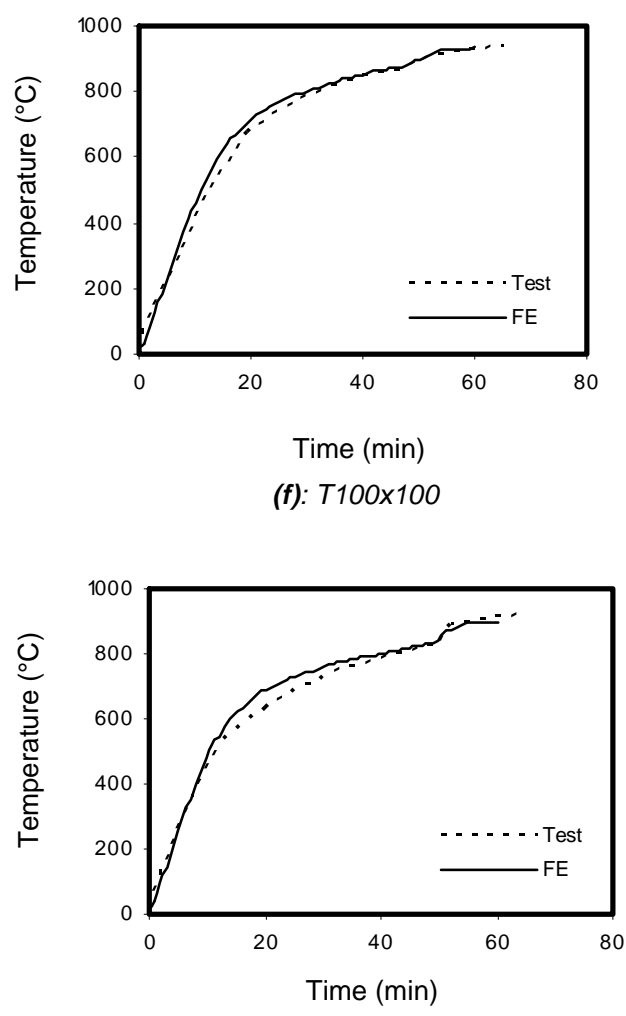

(h): $1120 \times 64$ 


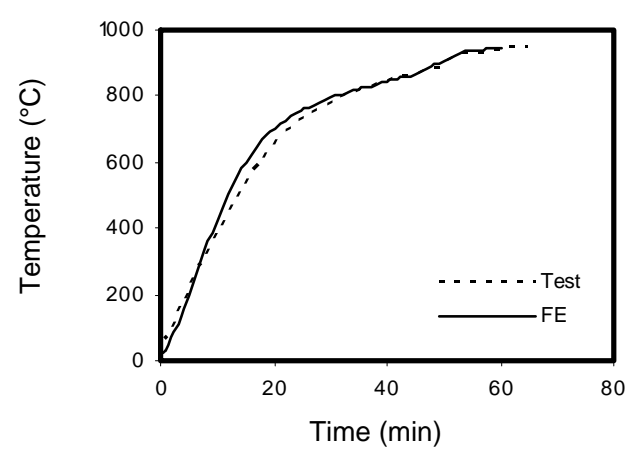

(i): $160 \times 82$

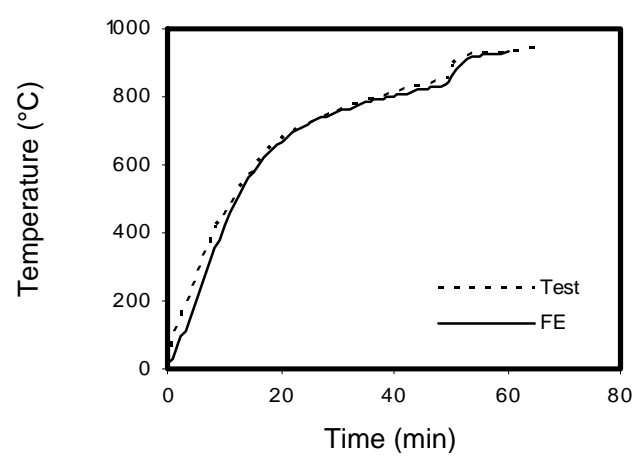

(k): RHS120x60

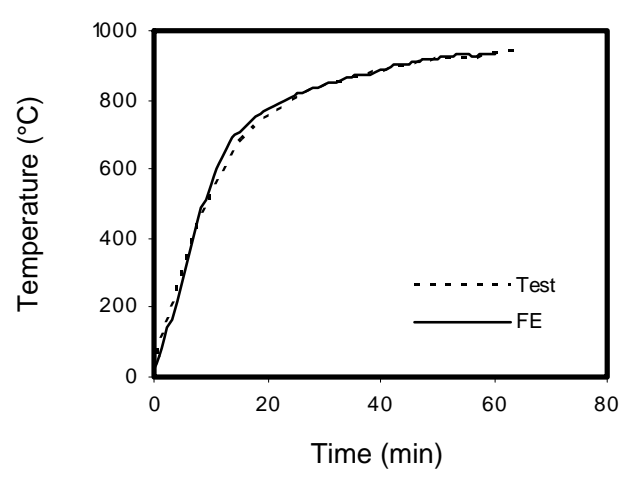

(m):RHS100×100

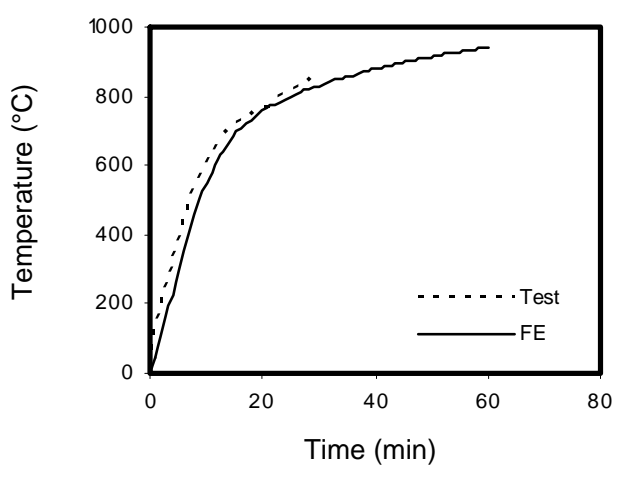

(o): RHS100x100 (CTICM)
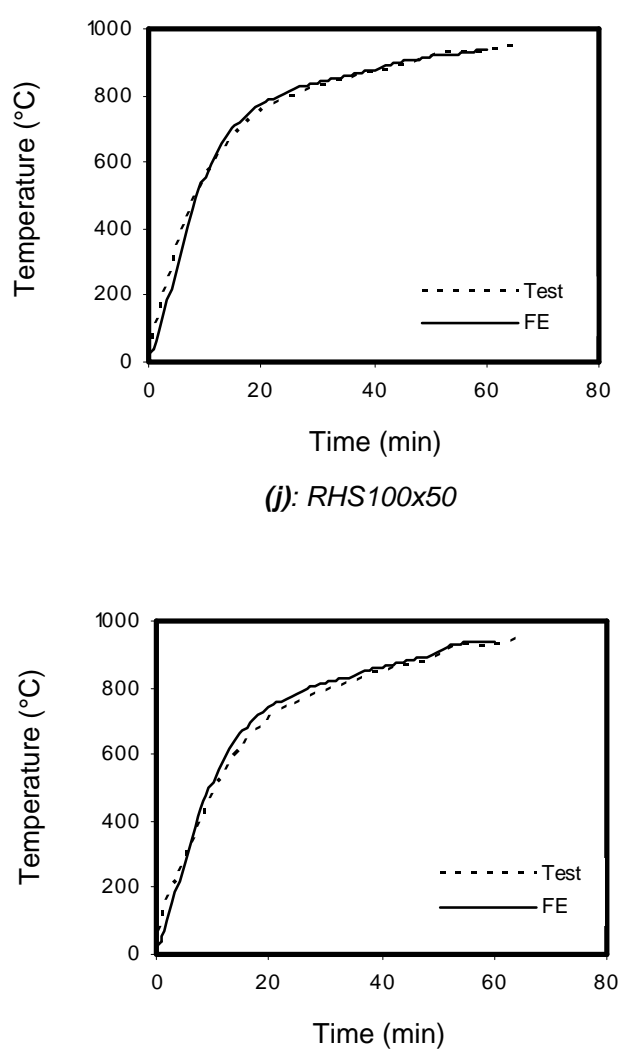

(I): RHS250×100

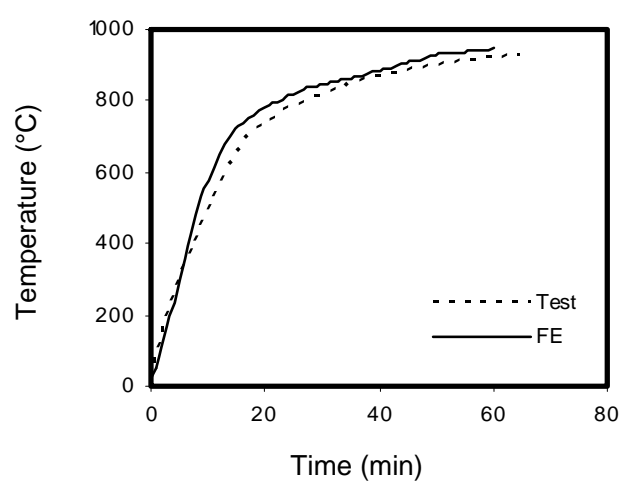

(n): RHS200×200

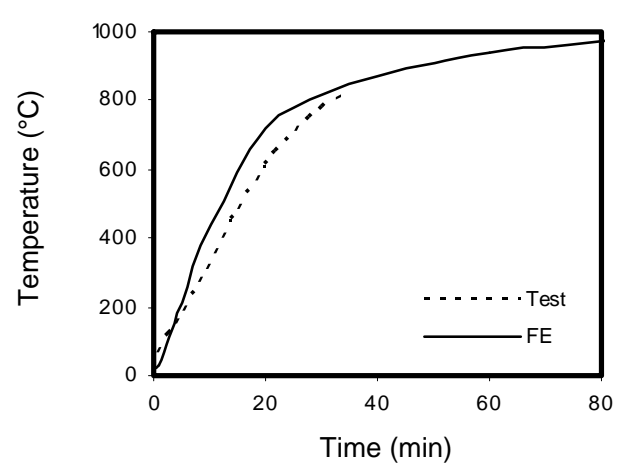

(p): RHS150x100 


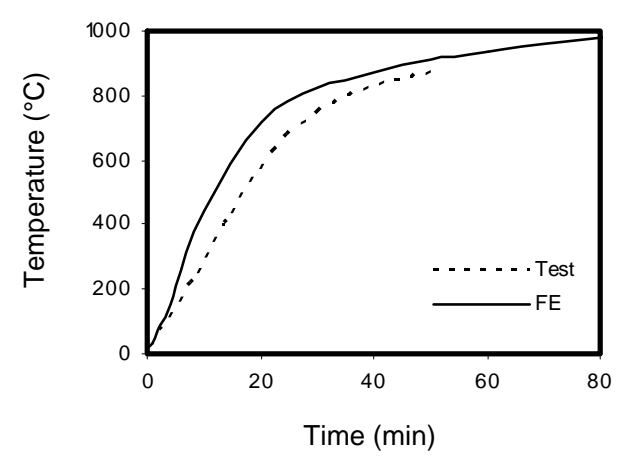

(q): RHS150x75

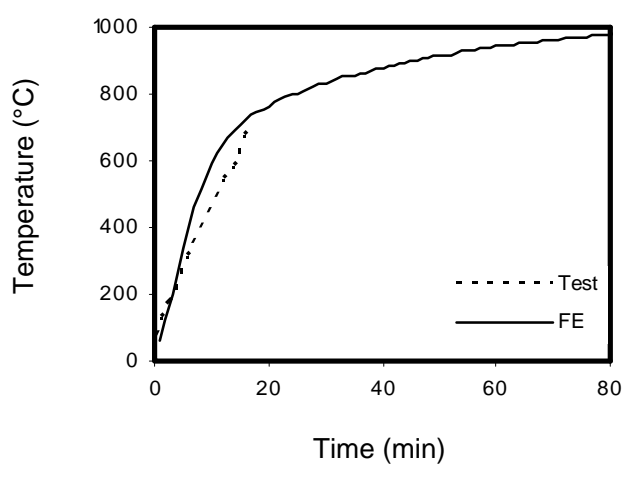

(s): $1200 \times 150$

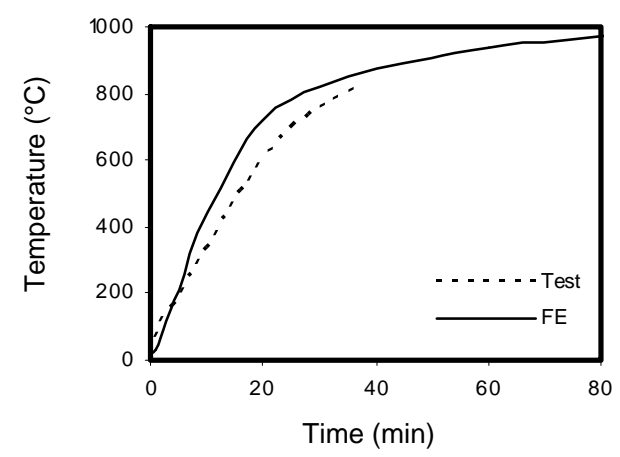

(r): RHS100 75

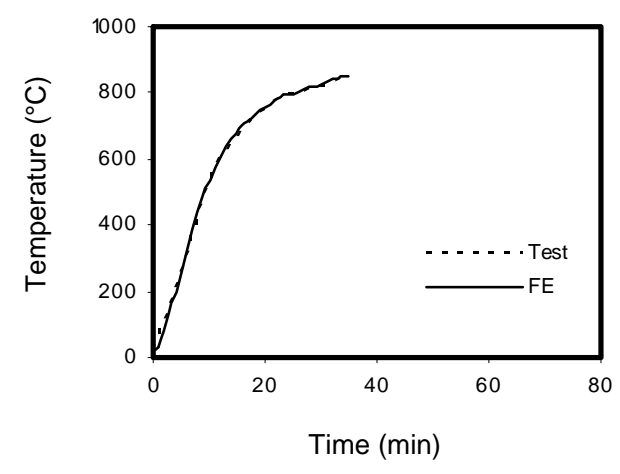

(t): RHS 40x40

Figure 7: Comparison between test and FE (without shadow effect) temperature development in sections exposed to fire on four sides 


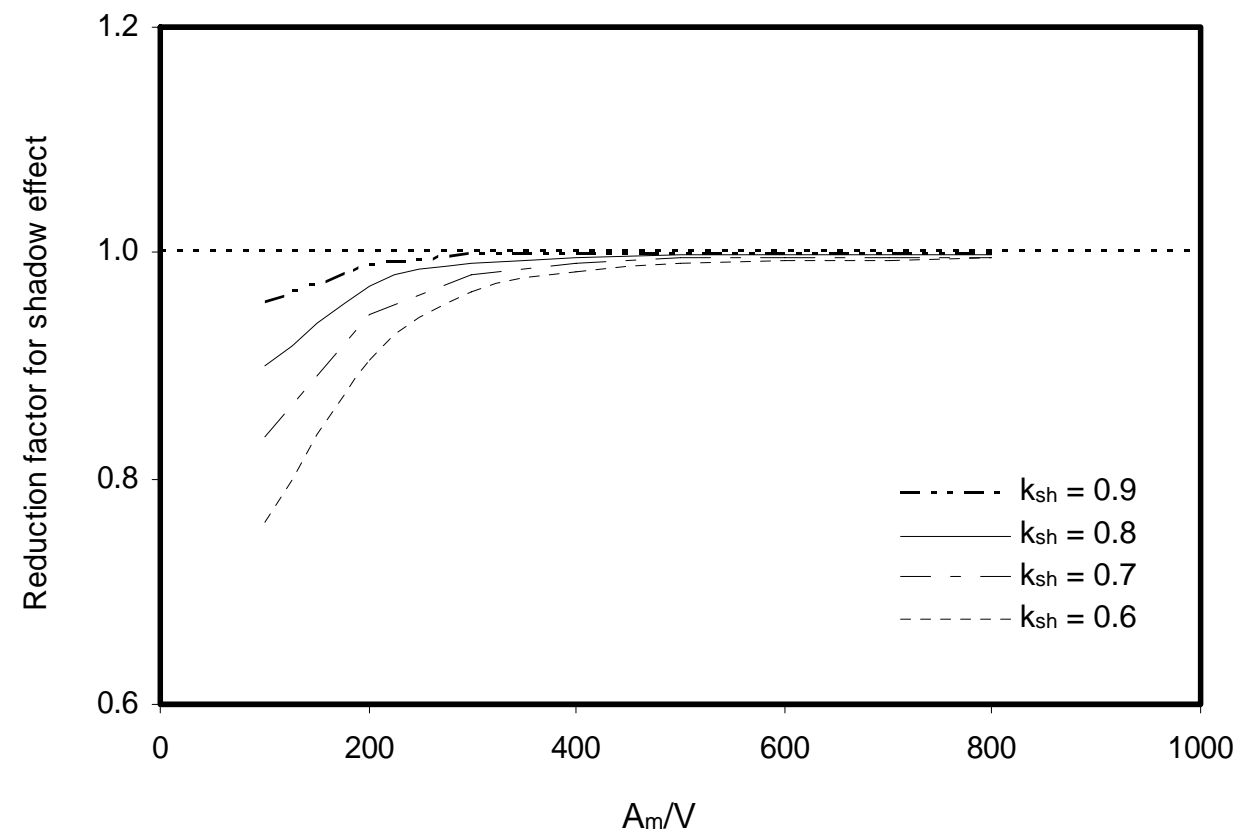

Figure 8: Significance of shadow effect on temperature development for varying $k_{s h}$ and $A_{m} / V$ ratio at 20 minutes exposure time to ISO-834 

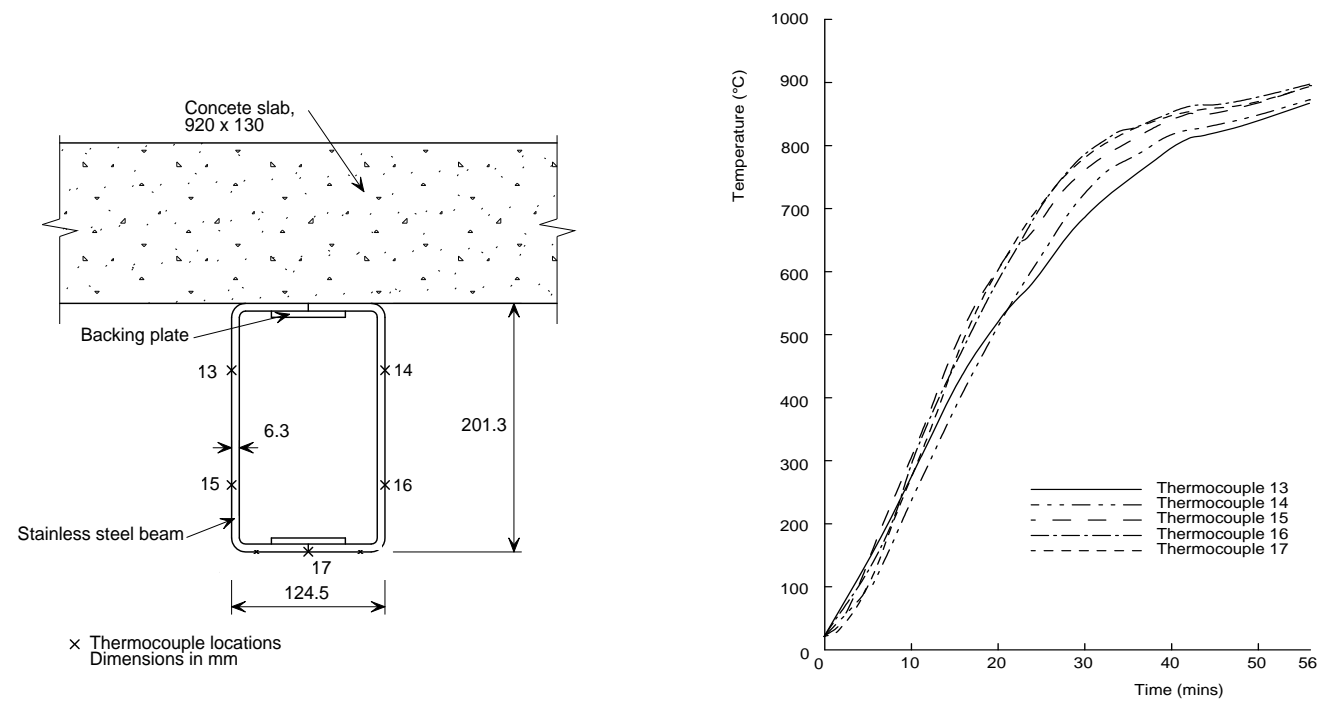

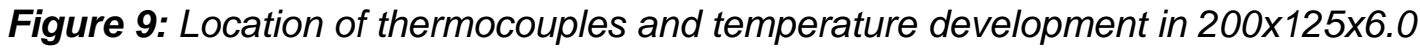
RHS beam 

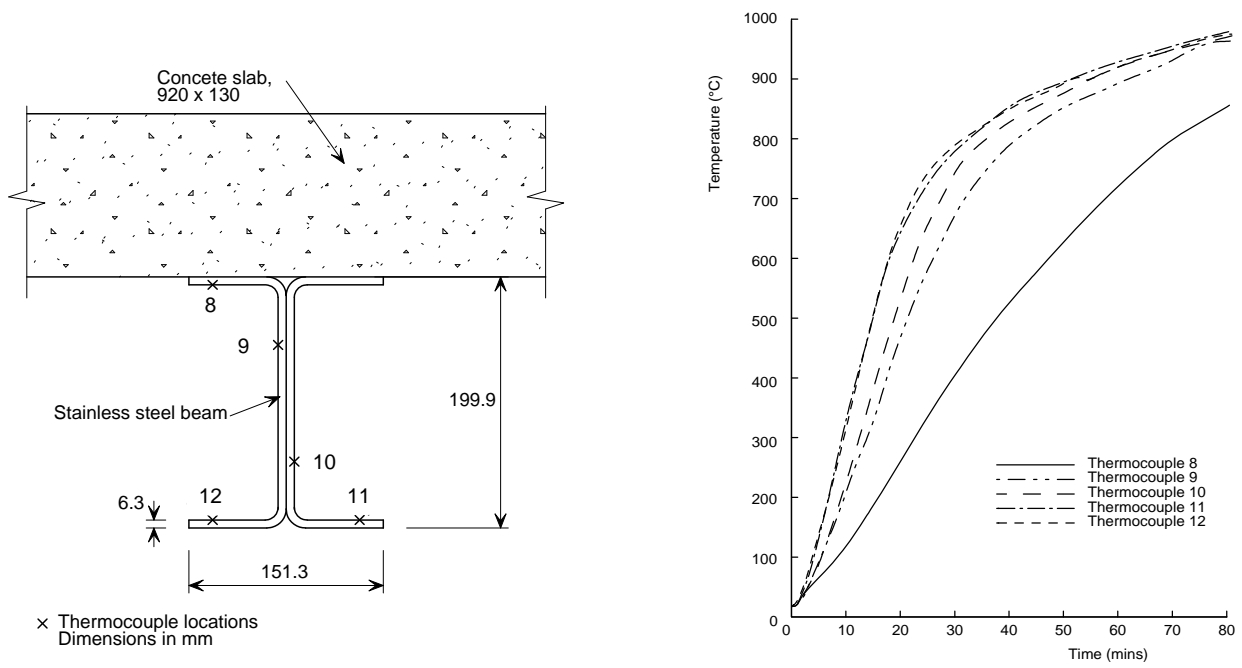

Figure 10: Location of thermocouples and temperature development in 200x150x6 Isection beam 

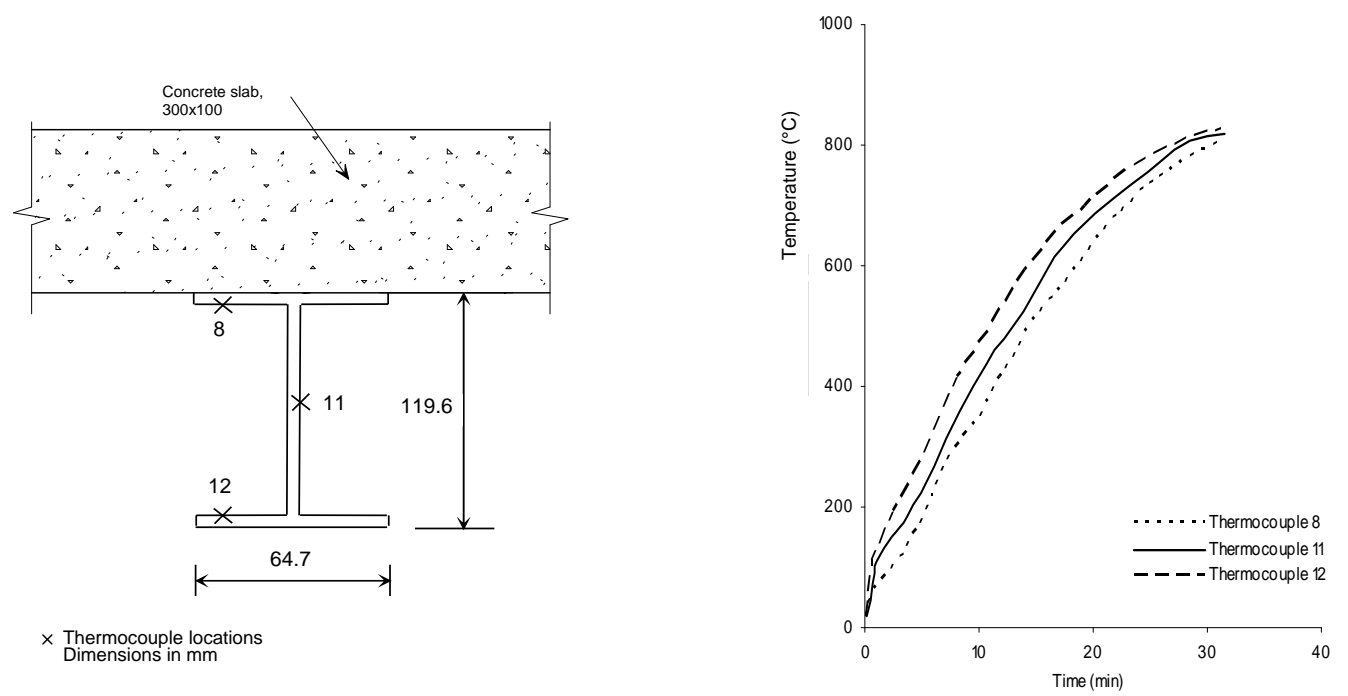

Figure 11: Location of thermocouples and temperature development in 120x64 CTICM I-section beam 


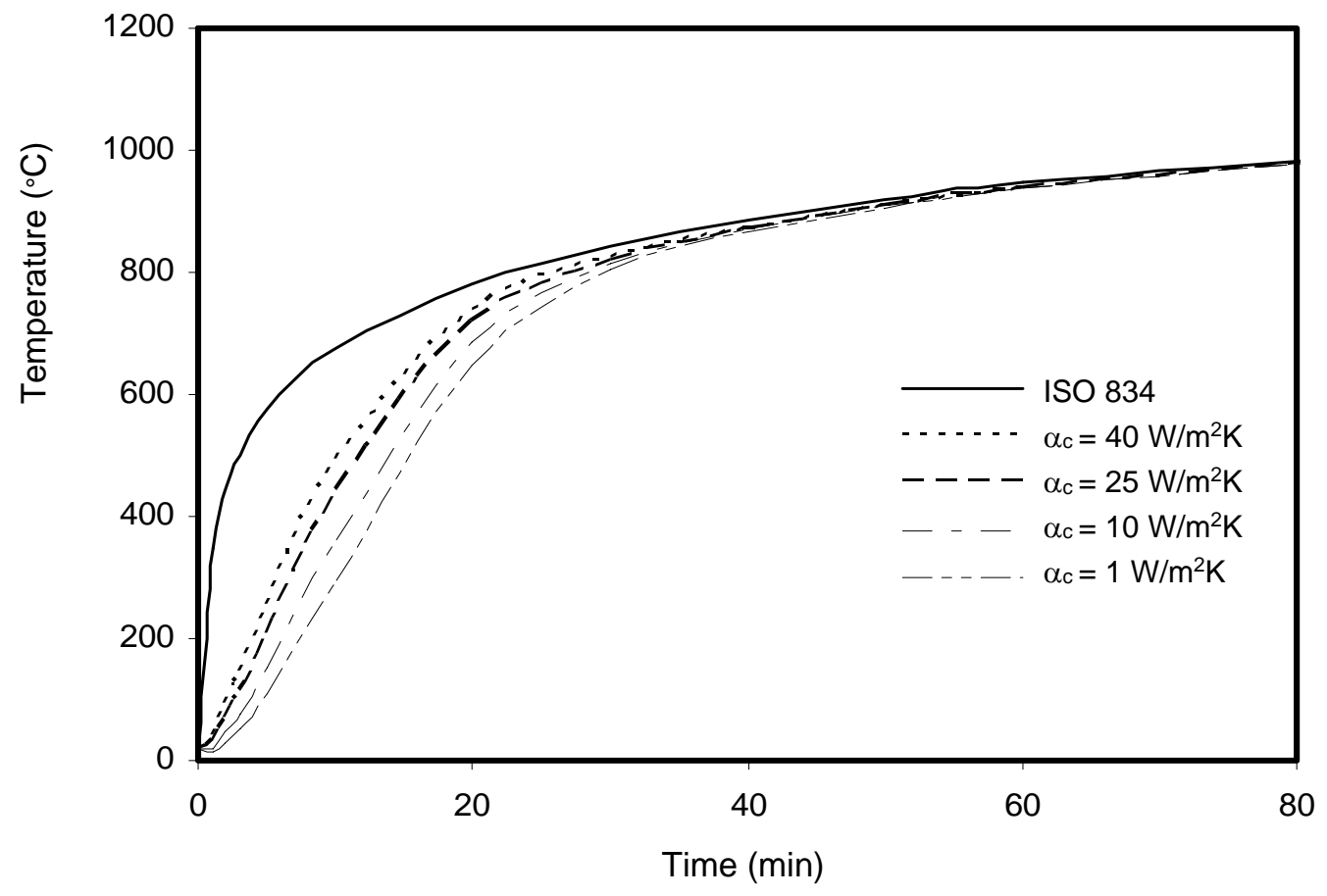

Figure 12: Comparison of temperature development in RHS 150x75x6 with constant emissivity $\left(\varepsilon_{m}=0.4\right)$ and varying heat transfer coefficient 


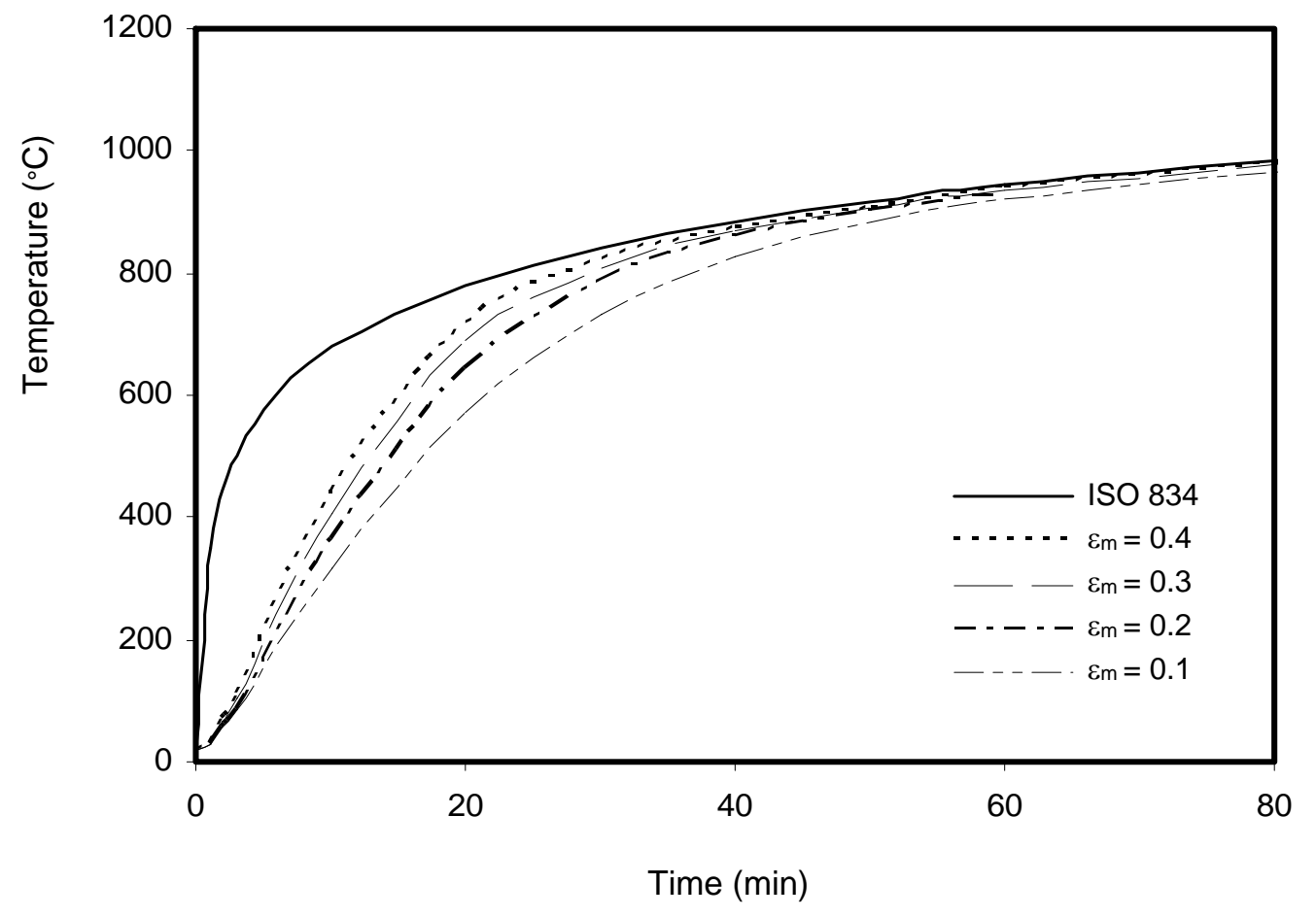

Figure 13: Comparison of temperature development in RHS 150x75x6 with constant heat transfer coefficient $\left(\alpha_{c}=25 \mathrm{~W} / \mathrm{m}^{2} \mathrm{~K}\right)$ and varying emissivity 


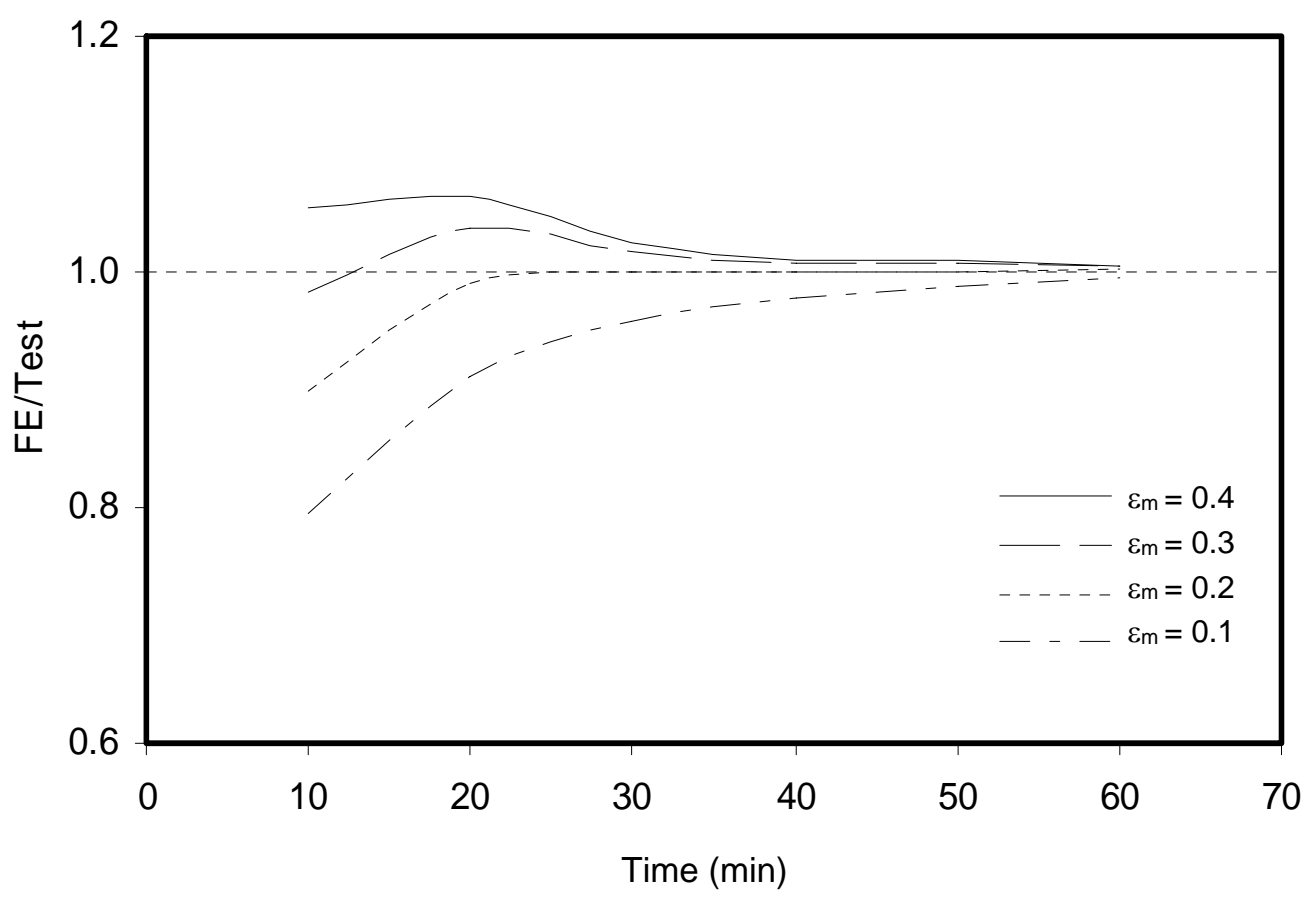

Figure 14: Comparison of FE/test temperature for $\alpha_{c}=25 \mathrm{~W} / \mathrm{m}^{2} \mathrm{~K}$ and varying emissivity 


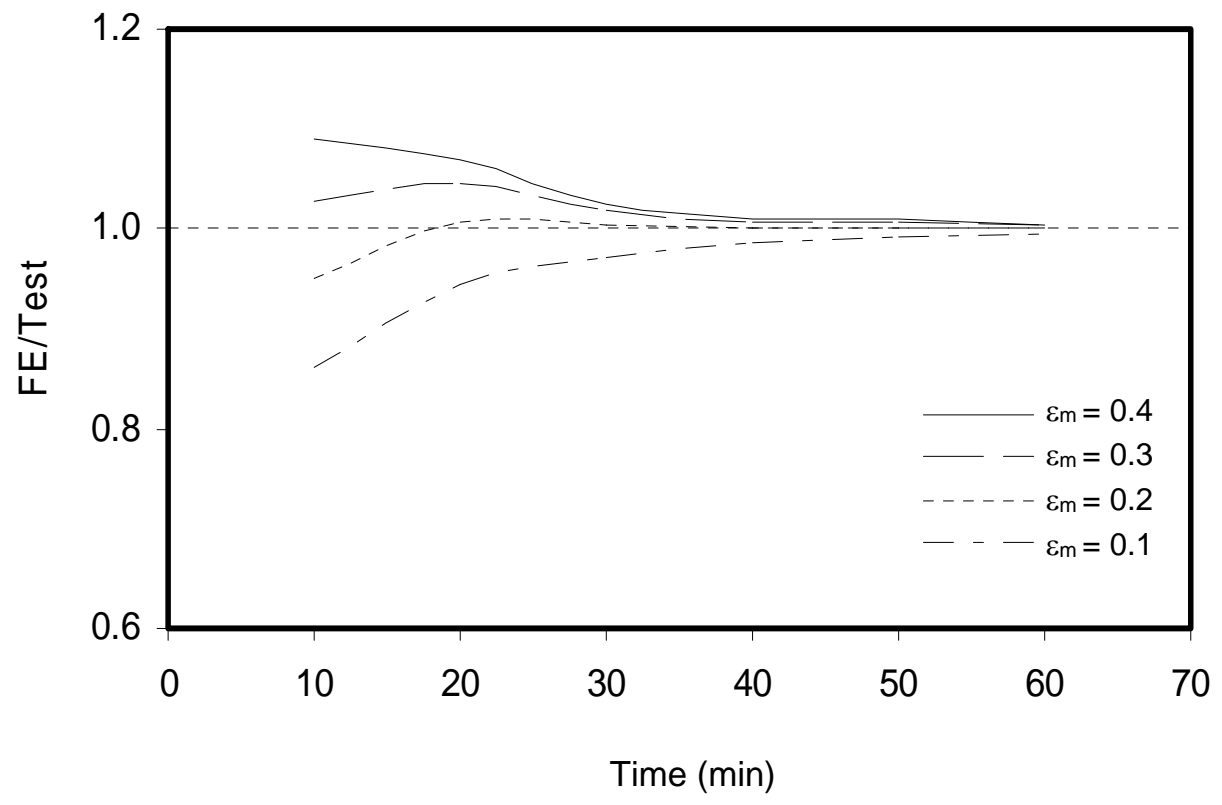

Figure 15: Comparison of FE/test temperature for $\alpha_{c}=30 \mathrm{~W} / \mathrm{m}^{2} \mathrm{~K}$ and varying emissivity 


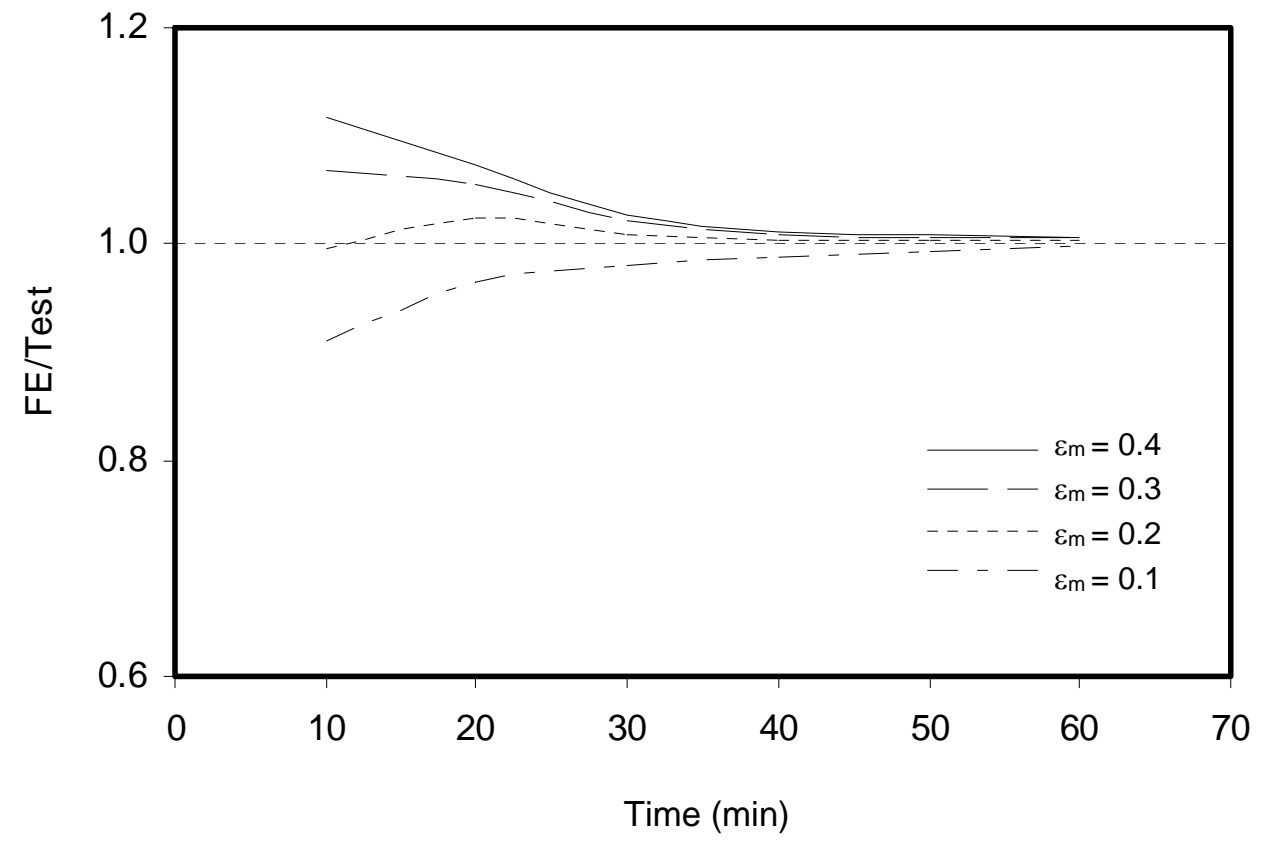

Figure 16: Comparison of FE/test temperature for $\alpha_{c}=35 \mathrm{~W} / \mathrm{m}^{2} \mathrm{~K}$ and varying emissivity 


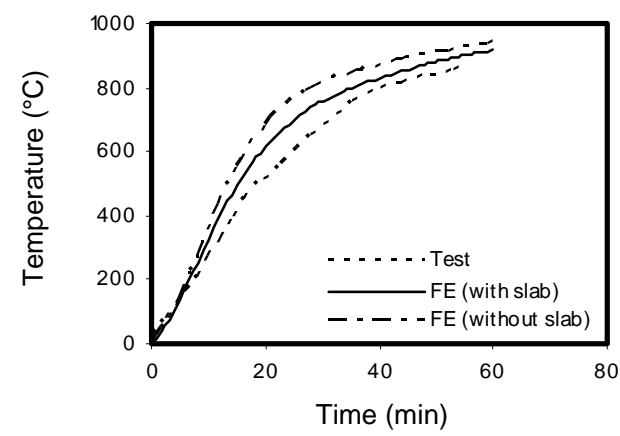

(a): Thermocouple 13

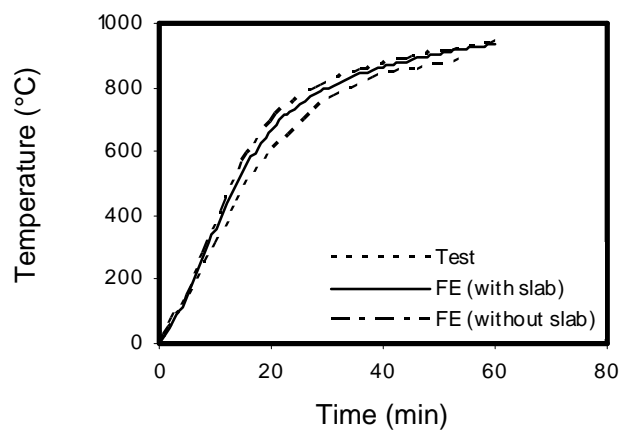

(c): Thermocouple 15

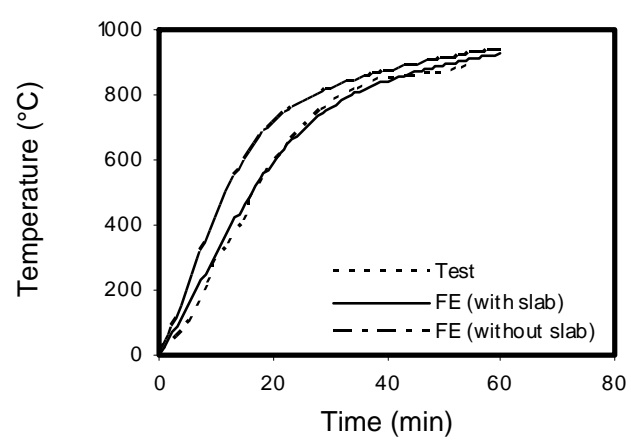

(e): Thermocouple 17

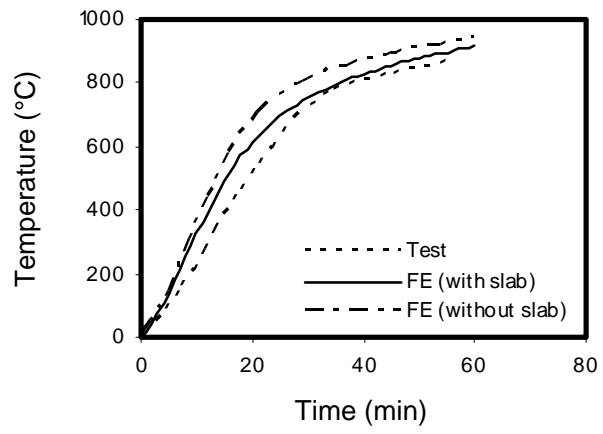

(b): Thermocouple 14

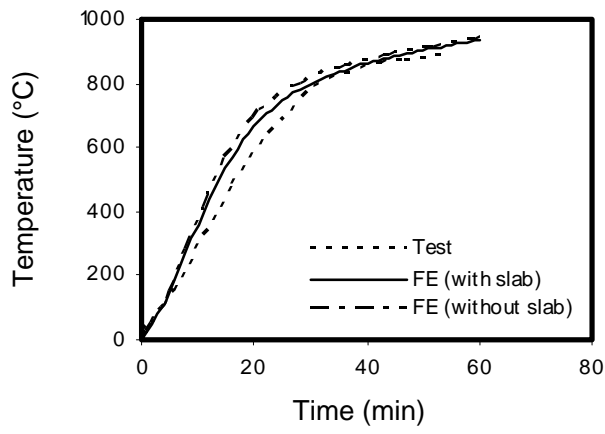

(d): Thermocouple 16

Figure 17: Comparison between FE and test temperature development in 200x125x6.0 RHS beam section at different thermocouple locations 


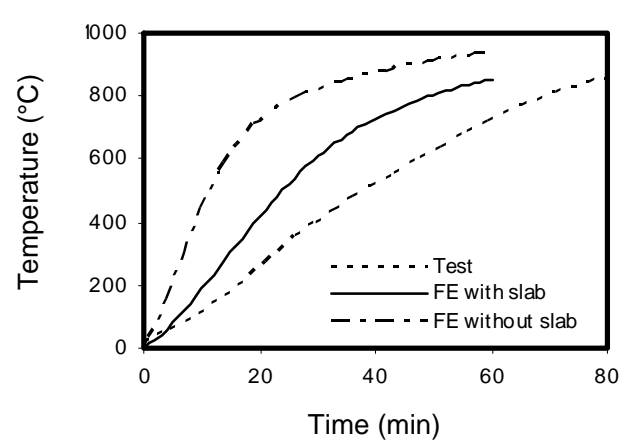

(a): Thermocouple 8

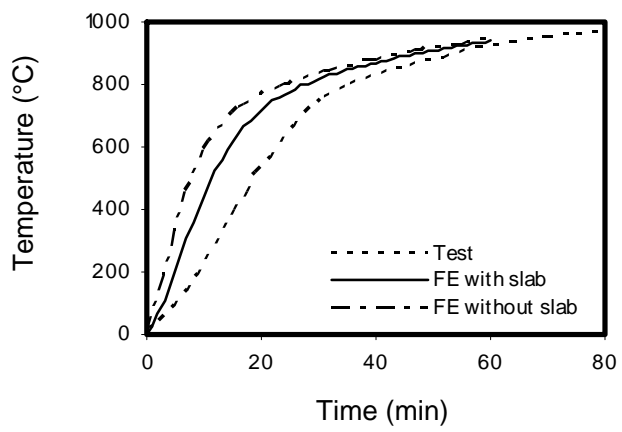

(c): Thermocouple 10

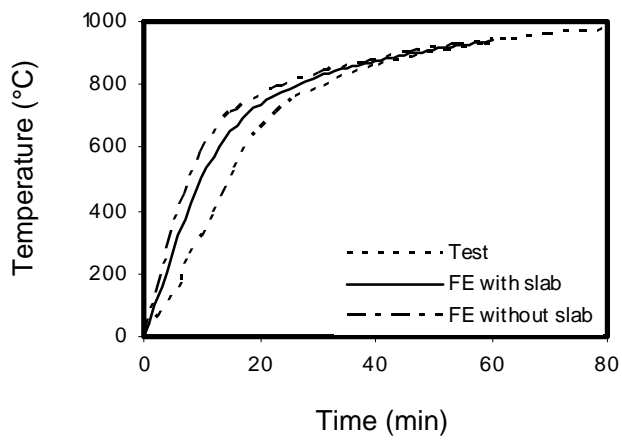

(e): Thermocouple 12

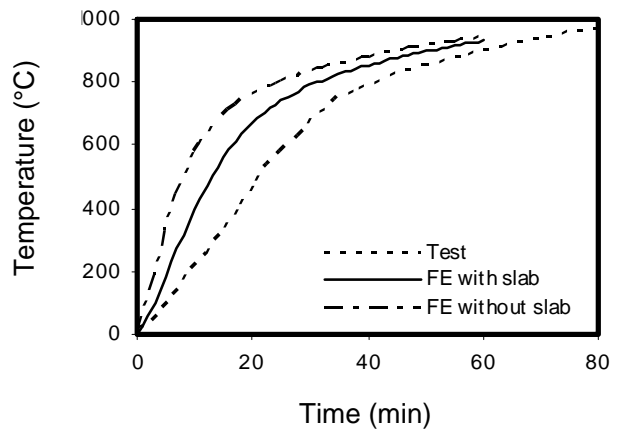

(b): Thermocouple 9

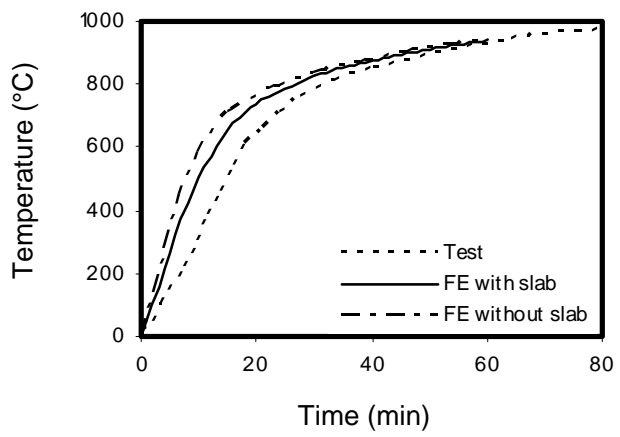

(d): Thermocouple 11

Figure 18: Comparison between FE and test temperature development in 200x150x6 Isection beam at different thermocouple locations 


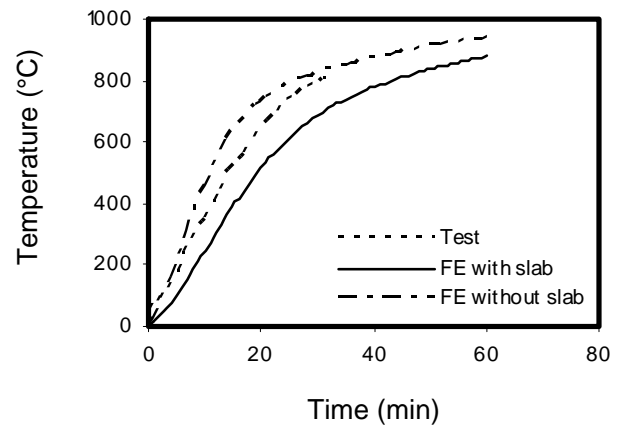

(a): Thermocouple 8

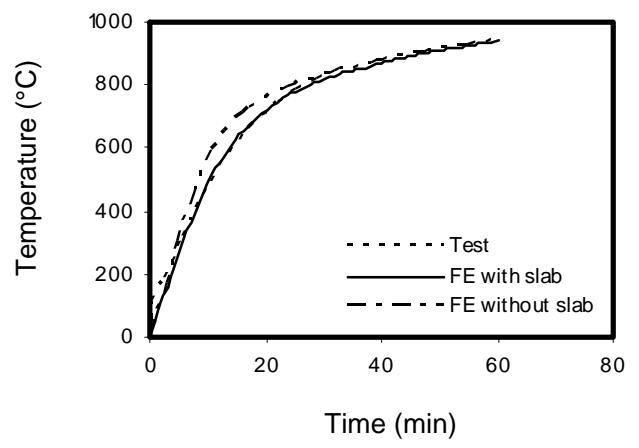

(c): Thermocouple 12

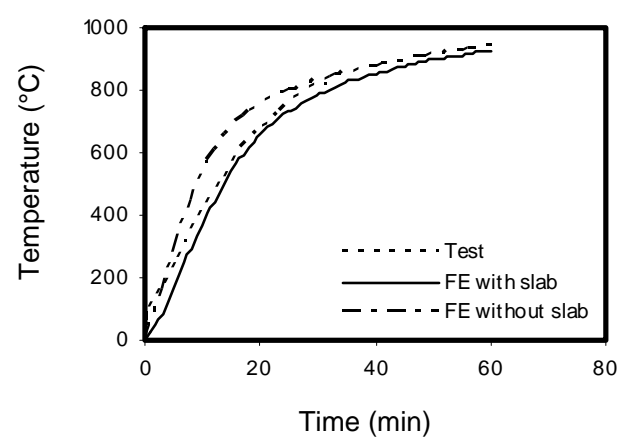

(b): Thermocouple 11

Figure 19: Comparison between FE and test temperature development in 120x64 CTICM I-section beam at different thermocouple locations 


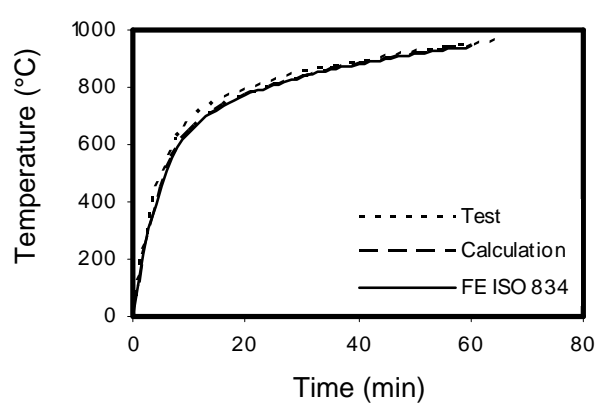

(a): $L 20 \times 20$

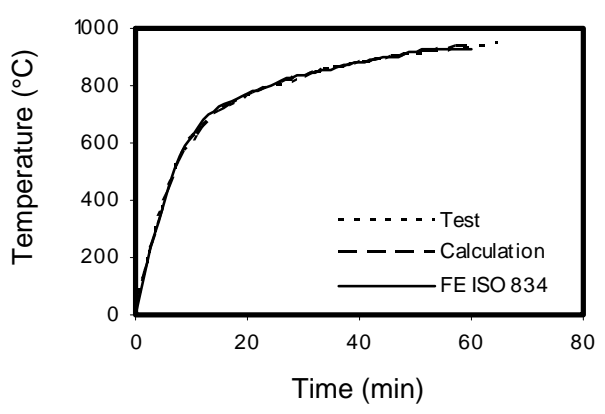

(c): T25X25

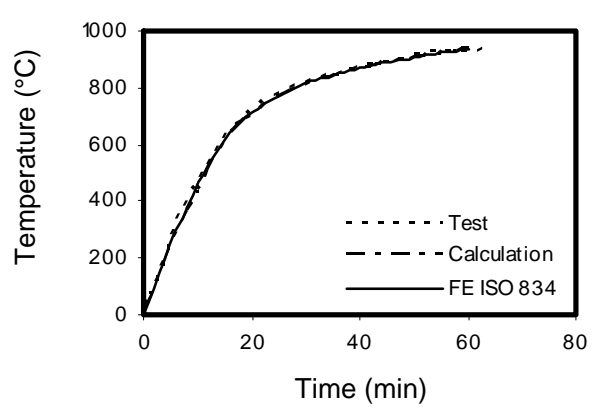

(b): $L 100 \times 100$

Figure 20: Comparison between FE, calculation model and test temperature development 


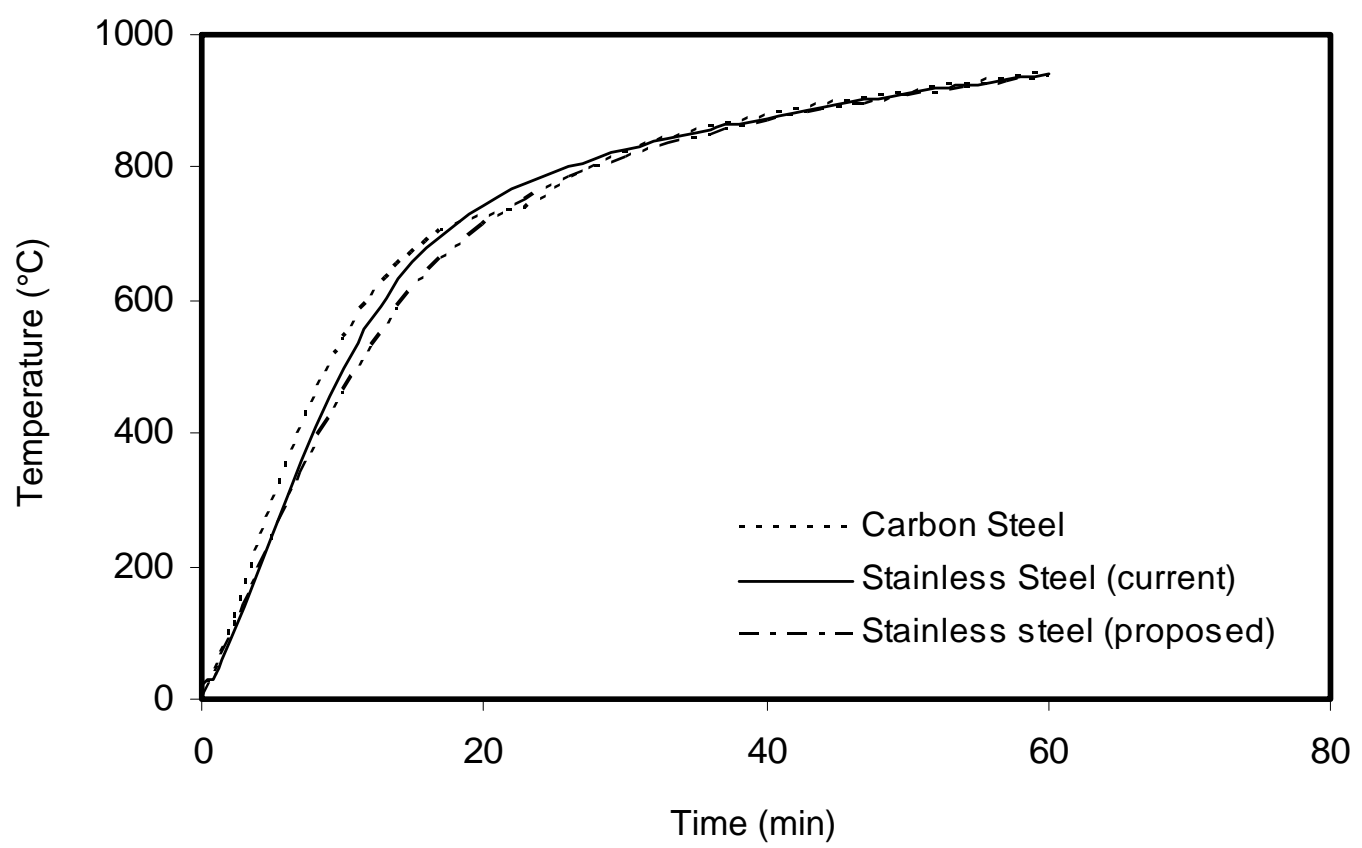

Figure 21: Temperature development of stainless steel and carbon steel 


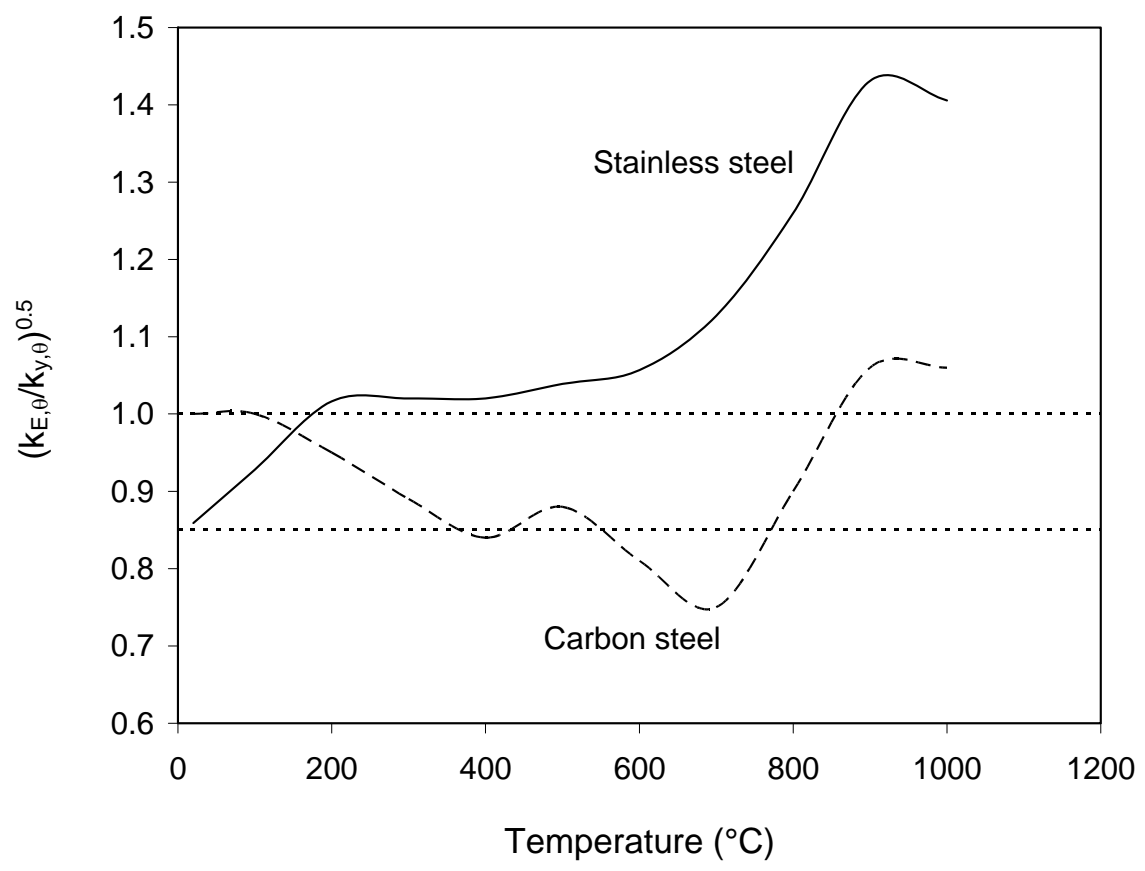

Figure 22: Variation of the modification factor $\left(k_{E, \theta} d k_{y, \theta}\right)^{0.5}$ with temperature 
Table 1: Summary of temperature development test specimens exposed to fire on 4 sides

\begin{tabular}{|c|c|c|c|c|}
\hline Reported by & $\begin{array}{l}\text { Section } \\
\text { shape }\end{array}$ & $\begin{array}{l}\text { Dimensions of the } \\
\text { section }(\mathrm{mm})\end{array}$ & $\begin{array}{l}\text { Section factor } \\
A_{\mathrm{m}} / V\left(\mathrm{~m}^{-1}\right)\end{array}$ & $\mathrm{k}_{\mathrm{sh}}$ \\
\hline \multirow{15}{*}{$\begin{array}{l}\text { Baddoo and Gardner } \\
\text { (2000) [5] }\end{array}$} & & $20 \times 20, t=3$ & 720.7 & 0.85 \\
\hline & & $100 \times 100, t=10$ & 210.5 & 0.85 \\
\hline & & $30 \times 15, t_{\mathrm{w}}=4, t_{\mathrm{f}}=4$ & 538.5 & 0.80 \\
\hline & & $160 \times 65, t_{\mathrm{w}}=7.5, t_{\mathrm{f}}=10.5$ & 234.7 & 0.81 \\
\hline & & $25 \times 25, t=4$ & 543.5 & 0.74 \\
\hline & & $100 \times 100, t=10$ & 210.5 & 0.77 \\
\hline & & $80 \times 40, t_{w}=4.5, t_{\mathrm{f}}=5.2$ & 426.5 & 0.70 \\
\hline & & $120 \times 64, t_{\mathrm{w}}=7.5, t_{\mathrm{f}}=7$ & 284.4 & 0.69 \\
\hline & & $160 \times 82, t_{\mathrm{w}}=10, t_{\mathrm{f}}=12$ & 188.7 & 0.69 \\
\hline & & $100 \times 50, t=4$ & 264.1 & 1.0 \\
\hline & & $120 \times 60, t=5$ & 211.8 & 1.0 \\
\hline & & $250 \times 100, t=4$ & 255.8 & 1.0 \\
\hline & & $100 \times 100, t=4$ & 260.4 & 1.0 \\
\hline & & $200 \times 200, t=4$ & 255.1 & 1.0 \\
\hline & & $100 \times 100, t=4, r=8$ & 258.6 & 1.0 \\
\hline \multirow{4}{*}{$\begin{array}{l}\text { Baddoo and Burgan } \\
\text { (1998) [4] }\end{array}$} & & $150 \times 100, t=6, r=4.5$ & 167.4 & 1.0 \\
\hline & & $150 \times 75, t=6, r=4.5$ & 168.2 & 1.0 \\
\hline & & $100 \times 75, t=6, r=4.5$ & 171.2 & 1.0 \\
\hline & & $200 \times 150, t=6, r=4.5$ & 234.7 & 0.65 \\
\hline Ala-Outinen (1999) [19] & & $40 \times 40, t=4, r=4$ & 273.5 & 1.0 \\
\hline
\end{tabular}


Table 2: Summary of temperature development test specimens exposed to fire on 3 sides

\begin{tabular}{|c|c|c|c|}
\hline Reported by & Section shape & $\begin{array}{c}\text { Dimensions of the } \\
\text { section }(\mathrm{mm})\end{array}$ & $\begin{array}{c}\text { Section factor } \\
A_{\mathrm{m}} / V\left(\mathrm{~m}^{-1}\right)\end{array}$ \\
\hline \multirow{2}{*}{$\begin{array}{c}\text { Baddoo and Burgan } \\
(1998)[4]\end{array}$} & $200 \times 125, t=6, \mathrm{r}=4.5$ & 163.9 \\
\cline { 2 - 4 } & - & $200 \times 150, t=6, \mathrm{r}=4.5$ & 169.5 \\
\hline $\begin{array}{c}\text { Baddoo and Gardner } \\
\text { (2000) [5] }\end{array}$ & $-120 \times 64, t_{\mathrm{w}}=7.9, t_{\mathrm{f}}=7.3$ & 271.8 \\
\hline
\end{tabular}


Table 3: Comparison of FE/test temperatures for all structural stainless steel temperature development tests with $\alpha_{c}=25 \mathrm{~W} / \mathrm{m}^{2} \mathrm{~K}$ and $\varepsilon_{m}=0.4$

\begin{tabular}{|c|c|c|c|c|c|c|}
\hline \multirow{3}{*}{ Specimens } & \multicolumn{6}{|c|}{ FE/Test temperatures $\left(\alpha_{c}=25 \mathrm{~W} / \mathrm{m}^{2} \mathrm{~K}, \varepsilon_{\mathrm{m}}=0.4\right)$} \\
\hline & \multicolumn{6}{|c|}{ Time (mins) } \\
\hline & 10 & 20 & 30 & 40 & 50 & 60 \\
\hline L20x20x3 & 0.93 & 0.98 & 0.98 & 0.99 & 1.00 & 0.99 \\
\hline L100×100x10 & 0.96 & 1.03 & 1.02 & 1.02 & 1.01 & 1.01 \\
\hline U30x15x4 & 1.04 & 1.02 & 1.01 & 1.01 & 1.00 & 1.01 \\
\hline U160x65 & 0.86 & 0.97 & 1.00 & 1.00 & 1.00 & 0.99 \\
\hline$T 25 \times 25 \times 4$ & 0.99 & 1.01 & 1.01 & 1.01 & 1.01 & 1.00 \\
\hline $\mathrm{T} 100 \times 100 \times 10$ & 0.92 & 1.01 & 1.01 & 1.00 & 1.00 & 1.00 \\
\hline $180 \times 40$ & 1.04 & 1.04 & 1.02 & 1.01 & 1.01 & 1.01 \\
\hline 1120x64 & 0.93 & 1.06 & 1.04 & 1.01 & 1.00 & 0.99 \\
\hline I160x82 & 0.88 & 1.01 & 1.00 & 1.00 & 1.01 & 1.01 \\
\hline RHS 100x50x4 & 1.02 & 1.03 & 1.01 & 1.01 & 1.00 & 1.01 \\
\hline RHS $120 \times 60 \times 5$ & 0.92 & 1.00 & 1.00 & 0.99 & 0.99 & 1.00 \\
\hline RHS $250 \times 100 \times 4$ & 1.09 & 1.05 & 1.03 & 1.02 & 1.01 & 1.01 \\
\hline RHS $100 \times 100 \times 4$ & 1.08 & 1.03 & 1.01 & 1.01 & 1.01 & 1.00 \\
\hline RHS 200x200x4 & 1.18 & 1.07 & 1.03 & 1.02 & 1.03 & 1.03 \\
\hline RHS $150 \times 100 \times 6$ & 1.25 & 1.16 & 1.09 & - & - & - \\
\hline RHS 150x75x6 & 1.54 & 1.24 & 1.10 & 1.06 & 1.04 & - \\
\hline RHS $100 \times 75 \times 6$ & 1.32 & 1.19 & 1.08 & - & - & - \\
\hline 1200x150x6 & 1.02 & 1.32 & - & - & - & - \\
\hline RHS 40x40x4 & 1.02 & 1.01 & 1.01 & - & - & - \\
\hline RHS $100 \times 100 \times 4$ & 0.89 & 0.99 & 0.97 & - & - & - \\
\hline Mean & 1.04 & 1.06 & 1.02 & 1.01 & 1.01 & 1.00 \\
\hline Overall mean & \multicolumn{6}{|c|}{1.03} \\
\hline COV & 0.162 & 0.088 & 0.034 & 0.015 & 0.014 & 0.010 \\
\hline
\end{tabular}


Table 4: Mean FE/test temperature values from table 3 for $\alpha_{c}=25 \mathrm{~W} / \mathrm{m}^{2} \mathrm{~K}$ and varying emissivity $\varepsilon_{m}$

\begin{tabular}{c|cccc}
\hline \multirow{2}{*}{ Time (mins) } & \multicolumn{4}{|c}{ FE $/$ Test, $\alpha_{\mathrm{c}}=25 \mathrm{~W} / \mathrm{m}^{2} \mathrm{~K}$} \\
\cline { 2 - 5 } & $\varepsilon \mathrm{m}=0.4$ & $\varepsilon \mathrm{m}=0.3$ & $\varepsilon \mathrm{m}=0.2$ & $\varepsilon \mathrm{m}=0.1$ \\
\hline 10 & 1.06 & 0.98 & 0.90 & 0.80 \\
20 & 1.06 & 1.04 & 0.98 & 0.91 \\
30 & 1.02 & 1.02 & 1.00 & 0.96 \\
40 & 1.01 & 1.01 & 1.00 & 0.98 \\
50 & 1.01 & 1.01 & 1.00 & 0.99 \\
60 & 1.01 & 1.00 & 1.00 & 0.99 \\
\hline Mean & 1.03 & 1.01 & 0.98 & 0.94 \\
\hline COV & 0.025 & 0.017 & 0.041 & 0.081 \\
\hline
\end{tabular}


Table 5: Mean FE/test temperature values from table 3 for $\alpha_{c}=30 \mathrm{~W} / \mathrm{m}^{2} \mathrm{~K}$ and varying emissivity $\varepsilon_{m}$

\begin{tabular}{c|cccc}
\hline \multirow{2}{*}{ Time (mins) } & \multicolumn{4}{|c}{ FE/Test, $\alpha_{\mathrm{c}}=30 \mathrm{~W} / \mathrm{m}^{2} \mathrm{~K}$} \\
\cline { 2 - 5 } & $\varepsilon_{\mathrm{m}}=0.4$ & $\varepsilon \mathrm{m}=0.3$ & $\varepsilon_{\mathrm{m}}=0.2$ & $\varepsilon_{\mathrm{m}}=0.1$ \\
\hline 10 & 1.09 & 1.03 & 0.95 & 0.86 \\
20 & 1.07 & 1.05 & 1.01 & 0.94 \\
30 & 1.03 & 1.02 & 1.00 & 0.97 \\
40 & 1.01 & 1.01 & 1.00 & 0.99 \\
50 & 1.01 & 1.01 & 1.00 & 0.99 \\
60 & 1.01 & 1.00 & 1.00 & 1.00 \\
\hline Mean & 1.04 & 1.02 & 0.99 & 0.96 \\
\hline COV & 0.035 & 0.016 & 0.022 & 0.054 \\
\hline
\end{tabular}


Table 6: Mean FE/test temperature values from table 3 for $\alpha_{c}=35 \mathrm{~W} / \mathrm{m}^{2} \mathrm{~K}$ and varying emissivity $\varepsilon_{m}$

\begin{tabular}{c|cccc}
\hline \multirow{2}{*}{ Time $(\mathrm{mins})$} & \multicolumn{4}{|c}{ FE/Test, $\alpha_{\mathrm{c}}=35 \mathrm{~W} / \mathrm{m}^{2} \mathrm{~K}$} \\
\cline { 2 - 5 } & $\varepsilon_{\mathrm{m}}=0.4$ & $\varepsilon_{\mathrm{m}}=0.3$ & $\varepsilon_{\mathrm{m}}=0.2$ & $\varepsilon_{\mathrm{m}}=0.1$ \\
\hline 10 & 1.12 & 1.07 & 1.00 & 0.91 \\
20 & 1.07 & 1.05 & 1.02 & 0.97 \\
30 & 1.03 & 1.02 & 1.01 & 0.98 \\
40 & 1.01 & 1.01 & 1.00 & 0.99 \\
50 & 1.01 & 1.01 & 1.00 & 0.99 \\
60 & 1.01 & 1.01 & 1.00 & 1.00 \\
\hline Mean & 1.04 & 1.03 & 1.01 & 0.97 \\
\hline COV & 0.043 & 0.026 & 0.009 & 0.034 \\
\hline
\end{tabular}


Table 7: Distribution of $\alpha_{c}$ and $\varepsilon_{m}$ from parametric study on beams

\begin{tabular}{l|c|c}
\hline Component & $\alpha_{\mathrm{c}}\left(\mathrm{W} / \mathrm{m}^{2} \mathrm{~K}\right)$ & $\varepsilon_{\mathrm{m}}$ \\
\hline Concrete slab (bottom) & 5 & 0.6 \\
Concrete slab (top) & 10 & 0.6 \\
Beam (I-section web) & 10 & 0.2 \\
Beam (lower flange and RHS web) & 35 & 0.2 \\
Beam (I-section upper flange) & 10 & 0.2 \\
Beam (I-section lower flange) & 35 & 0.2 \\
\hline
\end{tabular}


Table 8: Comparison of test and predicted critical temperatures and fire resistances

\begin{tabular}{|c|c|c|c|c|c|c|}
\hline \multirow{2}{*}{$\begin{array}{l}\text { Nominal Section } \\
\text { Size of Column }\end{array}$} & \multicolumn{3}{|c|}{ Critical temperature $\left({ }^{\circ} \mathrm{C}\right)$} & \multicolumn{3}{|c|}{ Fire Resistance (minutes) } \\
\hline & Test & Eurocode $^{\mathrm{a}}$ & Proposed $^{b}$ & Test & Eurocode $^{\mathrm{a}}$ & Proposed $^{b}$ \\
\hline $150 \times 100 \times 6$ RHS & 801 & 731 & 737 & 32 & 20 & 23 \\
\hline 150x75×6 RHS & 883 & 851 & 851 & 51 & 35 & 37 \\
\hline 100x75x6 RHS & 806 & 759 & 763 & 36 & 22 & 25 \\
\hline $200 \times 150 \times 6][$ & 571 & 392 & 377 & 14 & 7 & 7 \\
\hline $100 \times 100 \times 4$ SHS & 835 & 778 & 783 & 27 & 22 & 24 \\
\hline $200 \times 200 \times 4$ SHS & 820 & 513 & 523 & 24 & 9 & 10 \\
\hline
\end{tabular}

Notes: ${ }^{a}{ }_{m}=0.4, \alpha_{c}=25 \mathrm{~W} / \mathrm{m}^{2} \mathrm{~K}$ (as recommended by prEN 1993-1-4 and EN 1991-1-2, respectively)

${ }^{\mathrm{b}} \mathrm{Em}_{\mathrm{m}}=0.2, \alpha_{\mathrm{c}}=35 \mathrm{~W} / \mathrm{m}^{2} \mathrm{~K}$ (proposed herein) 